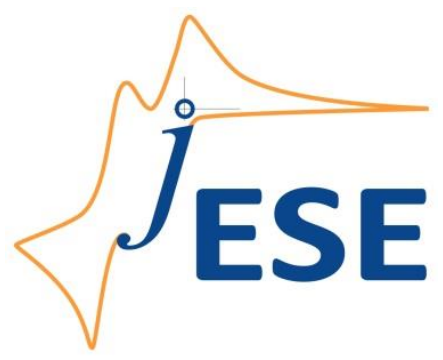

Open Access : : ISSN 1847-9286

www.jESE-online.org

Original scientific paper

\title{
Conduction mechanism in passive films on austenitic stainless steels in sulphate solutions
}

\section{Iva Betova}

Department of Chemistry, Technical University of Sofia, Kliment Ohridski Boulevard 8, 1000 Sofia, Bulgaria

${ }^{\square}$ Corresponding Author: iva betova@tu-sofia.bg; Tel.: +359 889295523

Received: December 7, 2014; Revised: March 15, 2015; Published: August 26, 2015

\begin{abstract}
The passive state of three commercial highly alloyed austenitic stainless steels is studied by voltammetric, contact electric resistance and impedance measurements in $0.5 \mathrm{M}$ sulphate solutions ( $\mathrm{pH}$ 2-7). The three materials self-passivate and are susceptible to transpassive dissolution. The electric properties of the passive films formed are only slightly dependent on alloy composition. The impedance response can be interpreted as due to both the electronic properties of a thin semiconductor film of variable stoichiometry and the ionic defect migration through that film limiting the metal dissolution rate in the passive state. A range of kinetic, transport and structural parameters characterising the passive film and its interfaces with the underlying alloys and the electrolyte solution are determined by a quantitative comparison of the MixedConduction Model to the experimental steady-state current and impedance data in a wide potential range. The relevance of the parameter values and the prospects of using the proposed approach to predict the steady-state metal dissolution rate and thus the general corrosion behaviour of stainless steels are discussed.
\end{abstract}

\section{Keywords}

Stainless steel, Metal dissolution, Passive film, Electrochemical impedance spectroscopy, Kinetic model

\section{Introduction}

The high resistance of highly alloyed stainless steels to both general and localised corrosion in a variety of electrolytic media is determined by the protective ability of thin passive films formed on their surfaces [1-5]. A quantitative correlation between the composition and structure of such films, as a function of the composition of the alloy substrate, their electrical and electrochemical 
properties and the extent of their interaction with the corrosive medium is yet to be established $[6,7]$. Such a correlation would make it possible to determine the extent of service life of a particular engineering material in a range of environments.

A comprehensive kinetic model of the passive film has to include electrochemical reactions of defect generation and consumption at the film interfaces with the underlying alloy and the electrolyte solution, as well as a description of the defect transport resulting in film growth and dissolution of alloy constituents through the oxide. So far, a substantial part of these requirements have been met by the Point Defect Model (PDM) developed extensively by Macdonald and coworkers [8-11] during the past couple of decades. A further development of the PDM has been carried out [12-15] to quantify the relationship between ionic point defect structure and electronic properties of the passive film. A view of that film in terms of the mixed-conduction model (MCM), is considered a likely approach that will be able to ascertain a quantitative structure-property relationship and thus would allow a deterministic prediction of corrosion rates in a wide variety of conditions. According to the PDM and the MCM, both lattice-destructive (film growth and dissolution) and lattice-preserving (dissolution of the substrate metal through the film) processes are treated as sequences of generation, transport and consumption of point defects (vacancies and interstitials). In turn, these defects play the role of electron donors or acceptors, ensuring the electronic conductivity of the film. With the assumption of high-field migration as the dominating mode of ion transport, usual electrochemical kinetics of the interfacial reactions and band-to-band tunnelling for the electron conduction, the steady-state current, conductivity vs. potential and small amplitude alternating current response of passive films forming on model ferrous alloys in acidic and slightly alkaline environments have been predicted [12-15].

In the present paper, the conduction in the passive films on three highly-alloyed austenitic stainless steels - AISI 904L (UNS N08904), 254 SMO (UNS S31254) and 654 SMO (UNS S32654) - in $0.5 \mathrm{M} \mathrm{Na}_{2} \mathrm{SO}_{4}$ solutions ( $\mathrm{pH} \mathrm{2,4}$ and 7) is investigated by voltammetry, contact electric resistance (CER) and electrochemical impedance techniques. Quantitative compositional data for passive films on comparable austenitic steels in similar environments indicate that the film is based on hydrated chromium-iron-molybdenum oxide [16-18]. Thus a modified version of the mixedconduction model featuring iron dissolution through the film mediated by interstitial cations and transpassive dissolution of chromium mediated by cation vacancies is proposed to account for the experimental data. A range of kinetic and transport parameters are estimated from a simultaneous fit of the steady-state current and impedance vs. potential data to the model equations. On the basis of the model predictions, the relative importance of iron and chromium dissolution as depending on $\mathrm{pH}$, electrode potential and alloy composition is assessed.

\section{Experimental}

\section{Electrodes and electrolytes}

Three types of commercial stainless steels, corresponding to AISI 904L (UNS N08904, Outokumpu Polarit Oy, Finland), 254SMO (UNS S31254, Avesta Sheffield Ab, Sweden) and 654SMO (UNS S32654, Avesta Sheffield Ab, Sweden) have been investigated. Their composition is given in Table 1. For the voltammetric and electrochemical impedance spectroscopic measurements, discs of the studied materials were pressed with a screw against rubber O-rings and embedded in PTFE holders to expose an area of $0.2 \mathrm{~cm}^{2}$ to the electrolyte. For the contact electric resistance (CER) measurements, electrode tips with a diameter of $2 \mathrm{~mm}$ (contact area ca. $0.015 \mathrm{~cm}^{2}$ ) made of the investigated materials and insulated by a multi-layered PTFE tape were used. The pre-treatment of 
the working electrodes consisted of polishing on 4000 grade emery paper, rinsing with Milli-Q ${ }^{\circledR}$ purified water and drying with hot air. Furthermore, the working electrodes were polarized in the hydrogen evolution region to establish reproducible initial electrochemical conditions. A threeelectrode cell featuring a $\mathrm{Pt}$ wire counter electrode and a saturated $\mathrm{KCl} \mid \mathrm{AgCl} / \mathrm{Ag}$ reference electrode ( $E=0.20 \mathrm{~V} v$ s. SHE) has been employed. All the potentials in the paper are given in the standard hydrogen scale. The measurements were performed at room temperature $\left(25^{\circ} \mathrm{C}\right)$ in $0.5 \mathrm{M}$ sulphate solutions ( $\mathrm{pH} \mathrm{2,4}$ and 7) prepared from p.a. $\mathrm{H}_{2} \mathrm{SO}_{4}, \mathrm{Na}_{2} \mathrm{SO}_{4}$ and Milli-Q ${ }^{\circledR}$ purified water and subsequently deaerated with $\mathrm{N}_{2}$ (99.999\%).

\section{Apparatus and procedures}

A Wenking LB 81M potentiostat and a HITEK PPR1 sweep generator were used for potential control in the CER measurements, the CER equipment being supplied by Cormet Ltd. A comprehensive description of the CER technique is given e.g. in Ref. 19. Voltammetric measurements have been carried out with an Autolab PGSTAT 20 controlled by GPES software (Eco Chemie, The Netherlands). To construct steady state current vs. potential curves, the current vs. time curve was recorded at each potential until a steady state current was reached (criterion: current variation with time $\leq 2 \%)$. Impedance spectra were measured at this steady state with the Autolab PGSTAT 20 equipped with a FRA2 module and controlled by FRA software (Eco Chemie, The Netherlands). A frequency range of $0.01-30,000 \mathrm{~Hz}$ at an AC amplitude of $20 \mathrm{mV}$ (rms) have been found to be appropriate. The reproducibility of the impedance spectra was $\pm 1.5 \%$ by magnitude and $\pm 2.5^{\circ}$ by phase angle. The validation of the impedance spectra was performed by checking the linearity condition, i.e. measuring spectra at AC signal amplitudes between 2 and 20 $\mathrm{mV}(\mathrm{rms})$, and the causality by a Kramers-Kronig test embedded in the FRA $4.9^{\circledR}$ software. The fitting of impedance spectra to selected transfer functions was based on Microcal Origin 6.0 software.

Table 1. Composition of the stainless steels used in the present investigation

\begin{tabular}{|l|c|c|c|c|c|c|c|c|c|c|}
\hline \multirow{2}{*}{ Alloy } & $\mathrm{Cr}$ & $\mathrm{Mo}$ & $\mathrm{Ni}$ & $\mathrm{Fe}$ & $\mathrm{Cu}$ & $\mathrm{C}$ & $\mathrm{Mn}$ & $\mathrm{S}$ & $\mathrm{N}$ \\
\cline { 2 - 10 } & \multicolumn{8}{|c|}{ Amount, wt \% } \\
\hline 654 SMO & 24 & 7.3 & 22 & balance & 0.43 & 0.01 & 2.0 & 0.001 & 0.5 \\
\hline 254 SMO & 20 & 6.1 & 18 & balance & 0.73 & 0.02 & 0.68 & 0.001 & 0.2 \\
\hline AISI 904L & 20 & 4.5 & 25 & balance & 1.50 & 0.01 & 1.43 & 0.001 & 0.06 \\
\hline
\end{tabular}

\section{Results}

\section{Current - potential and contact resistance - potential curves}

The current vs. potential curves of the studied materials measured using a linear sweep of $1 \mathrm{~m} \mathrm{Vs}^{-1}$ in the potential range from hydrogen evolution to transpassive dissolution are shown in Fig. 1a (0.5 $\mathrm{M} \mathrm{SO}_{4}{ }^{2-}, \mathrm{pH} 2$ solution), Fig. $2 \mathrm{a}\left(0.5 \mathrm{M} \mathrm{SO}_{4}{ }^{2-}, \mathrm{pH} 4\right.$ solution) and Fig. 3a (0.5 $\mathrm{M} \mathrm{SO}_{4}{ }^{2-}$, $\mathrm{pH} 7$ solution). The corresponding contact resistance vs. potential curves measured by the CER technique using the same sweep rate are presented in Figs $1 b-3 b$, respectively.

The current vs. potential curves exhibit typical features of self-passivating materials (Fig.1a-3a). Namely, a passivation range $(-0.2 \ldots 0.3 \mathrm{~V}$ at $\mathrm{pH} 2,-0.4 \ldots 0.2 \mathrm{~V}$ at $\mathrm{pH} 4$ and $-0.8 \ldots 0.0 \mathrm{~V}$ at $\mathrm{pH}$ 7) is followed by a passive region in which the current is quasi-independent on potential $(0.4 \ldots 1.0 \mathrm{~V}$ at $\mathrm{pH} 2,0 \ldots 1.0 \mathrm{~V}$ at $\mathrm{pH} 4$ and $\mathrm{pH}$ 7). The passive-to-transpassive transition is marked as a steep 
increase in the current density at around $1.0 \mathrm{~V}$. The current densities in the passivation range are the lowest for $654 \mathrm{SMO}$, i.e. this alloy passivates the most efficiently, in contrast to the transpassive range, in which the currents for $654 \mathrm{SMO}$ are the highest $[20,21]$. The obtained results are logical in view of the fact that 654SMO contains the highest amount of $\mathrm{Cr}$ and Mo among the investigated materials (Table 1) which enhance both the ability of self-passivation and the stability of the passive film. The $\mathrm{pH}$ of the solution influences the zero-current potential on the alloys, namely it is situated at ca.0.2 $\mathrm{V}$ at $\mathrm{pH} 2$ for all three materials, whereas at $\mathrm{pH} 4$ and 7 the zerocurrent potential is considerably for AISI 904L than for the other two materials. This could be due to different mechanisms of the oxygen reduction reaction on the studied alloys, however, a more detailed study of this mechanism is beyond the scope of the paper.
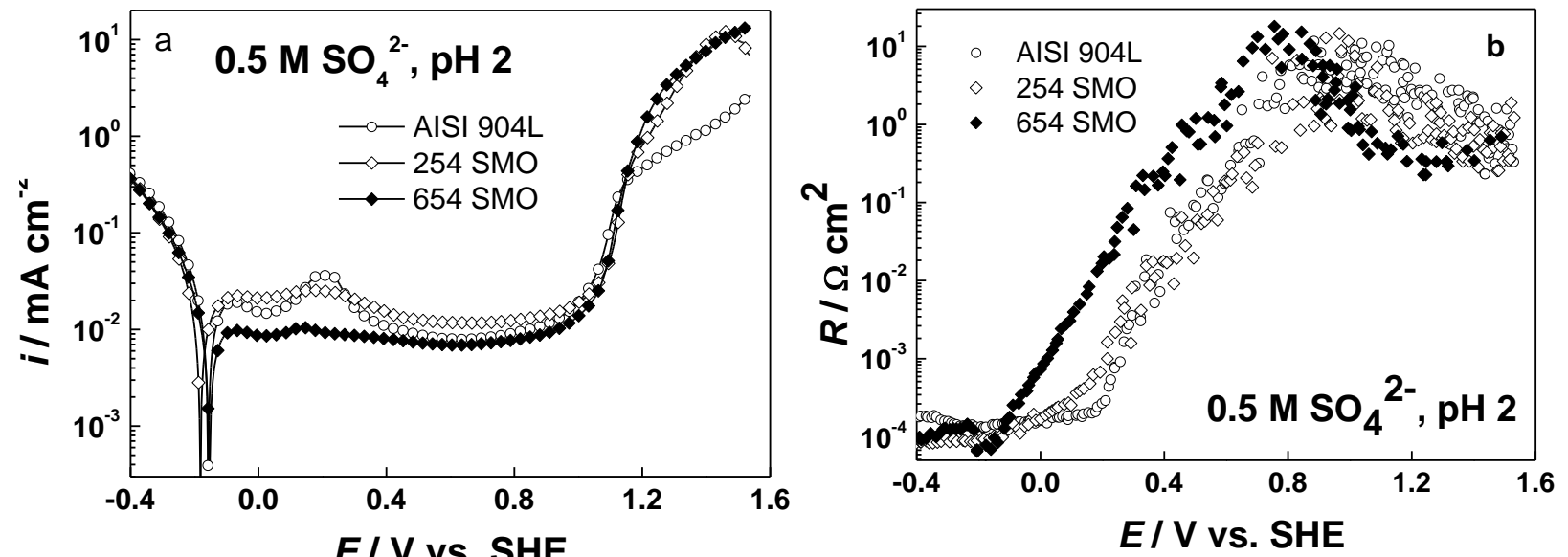

Figure 1. Current vs. potential curves (a) and resistance vs. potential curves (b) for the studied materials in $0.5 \mathrm{M} \mathrm{Na}_{2} \mathrm{SO}_{4}, \mathrm{pH}$ 2. Sweep rate $1 \mathrm{mV} \mathrm{s}^{-1}$

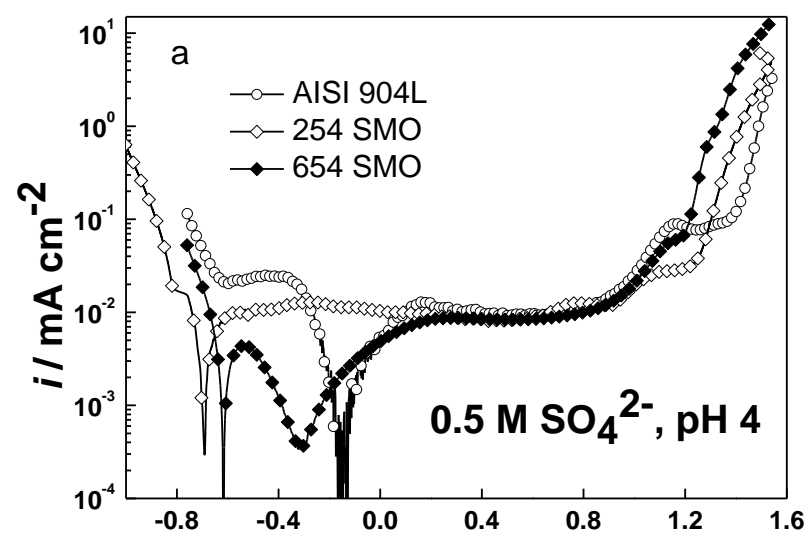

E / V vs. SHE

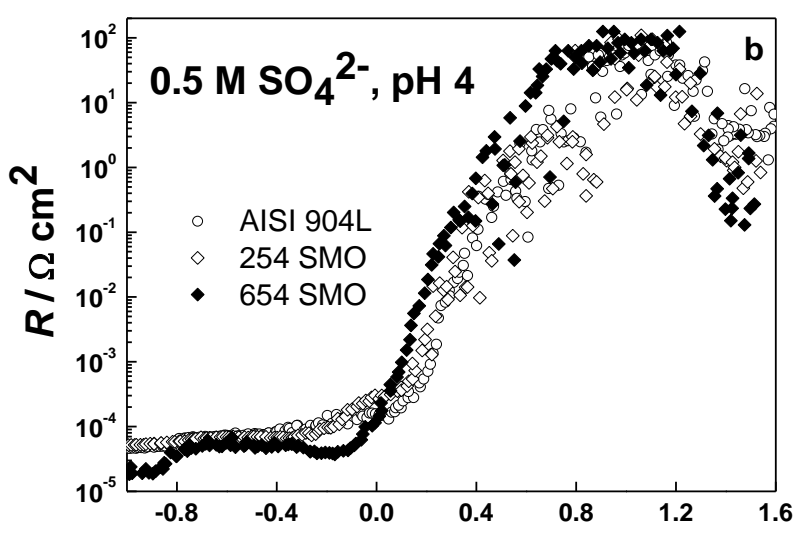

E / V vS. SHE

Figure 2. Current vs. potential curves (a) and resistance vs. potential curves (b) for the studied materials in $0.5 \mathrm{M} \mathrm{Na}_{2} \mathrm{SO}_{4}, \mathrm{pH}$ 4. Sweep rate $1 \mathrm{mV} \mathrm{s}^{-1}$

The contact resistance vs. potential curves are broadly analogous to those measured previously for ferritic steels in a $\mathrm{Na}_{2} \mathrm{SO}_{4}$ solution of $\mathrm{pH}_{5}$ [12], as well as recent measurements on a wide range of austenitic stainless steels in a $\mathrm{Na}_{2} \mathrm{SO}_{4}$ solution of $\mathrm{pH} 4.8$ reported by Kim et al. [22]. That is, a low and constant resistance characteristic of a thin conductive film is observed around the open circuit potential (Figs. 1b-3b). It is worth mentioning that the resistance stays low and constant also in the passivation region, which can be due to the very small thickness of the surface film allowing for direct tunnelling to take place through it. In the passive region, a quasi- 
exponential increase of the resistance by 4-6 orders of magnitude is observed followed by a resistance maximum slightly below the passive-to-transpassive transition potential (Figs $1 \mathrm{~b}-3 \mathrm{~b}$ ).

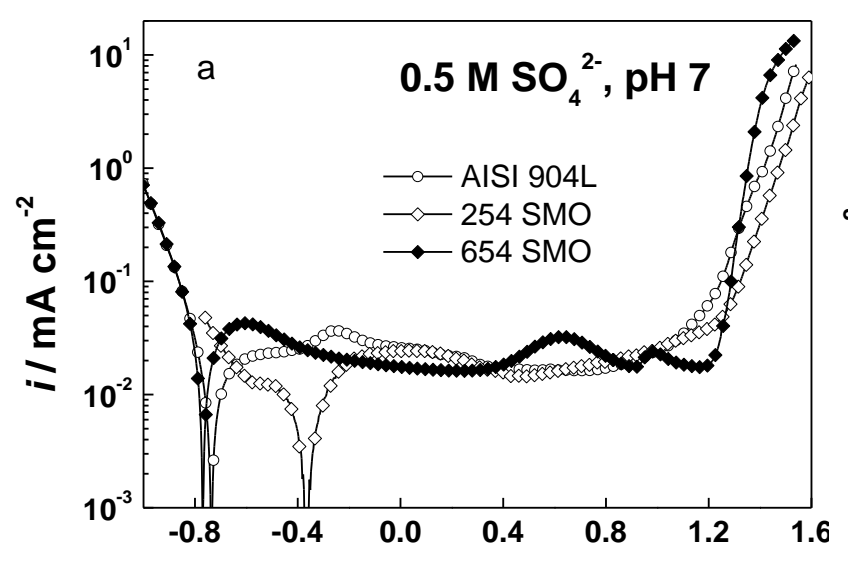

E / V vs. SHE

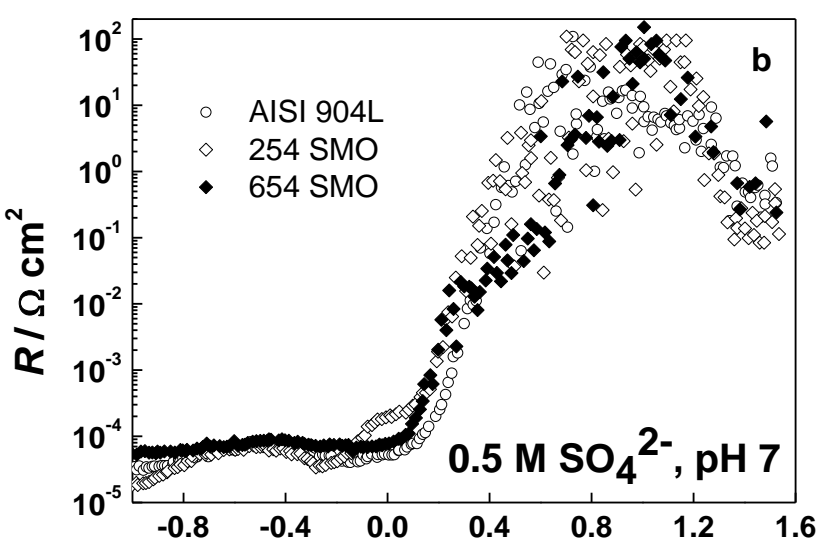

E / V vs. SHE

Figure 3. Current vs. potential curves (a) and resistance vs. potential curves (b) for the studied materials in $0.5 \mathrm{M} \mathrm{Na}_{2} \mathrm{SO}_{4}, \mathrm{pH}$ 7. Sweep rate $1 \mathrm{mV} \mathrm{s}^{-1}$.

This feature is indicative of film growth and depletion of the film of current carriers $[12,14]$. Such a depletion can be due to an overall decrease of the degree of non-stoichiometry of the oxide by its dehydration or the solid-state oxidation of divalent Fe in the film to trivalent [12-14, $23]$, i.e. to a redox reaction in the film accompanying film growth. It is worth mentioning that the maximum value of the resistance in the passive region obtained in the present work is ca. an order of magnitude lower than that measured previously for ferritic steels [12]. This may be related to the presence of $\mathrm{Ni}(\mathrm{II})$ in the film $[16,18,23]$ increasing the overall degree of non-stoichiometry. In this connection, it has been demonstrated that the maximum resistance of passive films on $\mathrm{Ni}-\mathrm{Cr}$ alloys is considerably lower than the corresponding resistance of the films on $\mathrm{Fe}-\mathrm{Cr}$ alloys in sulphate solutions [25]. The resistance vs. potential curves in the $\mathrm{pH} 4$ and $\mathrm{pH} 7$ solutions are very close to each other regardless of the material (Figs. $2 b, 3 b$ ) and seem to demonstrate that the electrical properties of the passive films on all the materials are nearly identical in the present experimental conditions.

As a conclusion, it can be stated that the voltammetric and contact resistance measurements allows to define a passive region in which the steady-state ionic conductivity and the electronic properties of the surface film are only slightly affected by potential. For potentials below that region, the degree of the non-stoichiometry of the film is increased by the generation of lowvalence or high-valence ionic defects, and thus both the ionic and electronic conduction through the oxide are enhanced.

\section{Electrochemical impedance spectroscopy}

To adequately measure impedance spectra, the system under study needs to be in a steadystate. In the present work, impedance spectra were measured at a range of potentials after a steady-state current density was reached. Examples of current vs. time curves obtained for 254 SMO steel in the $\mathrm{pH} 2$ solution are shown in Figure 4. These curves are typical for passive film growth and are characterized by a quasi-linear decrease in log-log coordinates, the slope of the log-log plot being of the order of -0.8 in the passive region. Steady-state current densities are reached typically after $1 \mathrm{~h}$ of polarization. 


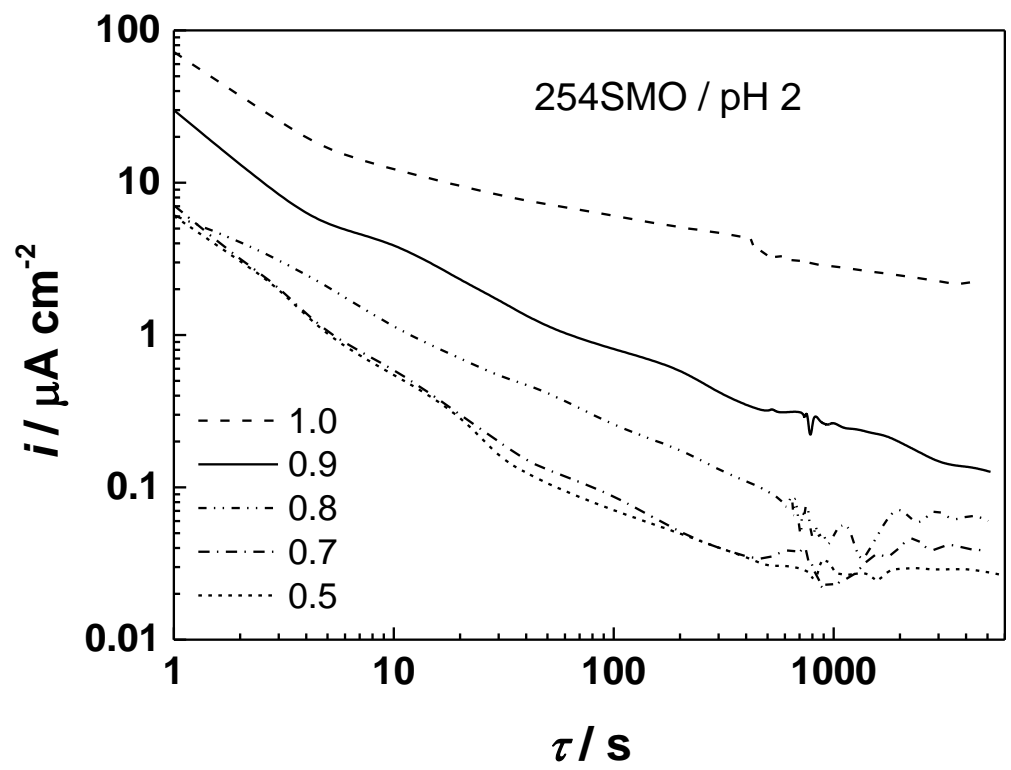

Figure 4. Current vs. time curves for $254 \mathrm{SMO}$ in a $\mathrm{pH} 2$ solution for potentials between 0.5 and $1.0 \mathrm{~V}$.

Impedance spectra in Bode coordinates for $254 \mathrm{SMO}$ in $0.5 \mathrm{M} \mathrm{SO}_{4}{ }^{2-}, \mathrm{pH} 2$ solution at a number of potentials ranging from the passivation region to the beginning of the transpassive region are shown in Fig. 5. The impedance response of this material in the transpassive region itself has been thoroughly discussed in previous papers $[20,21]$ and is out of the scope of the present investigation.
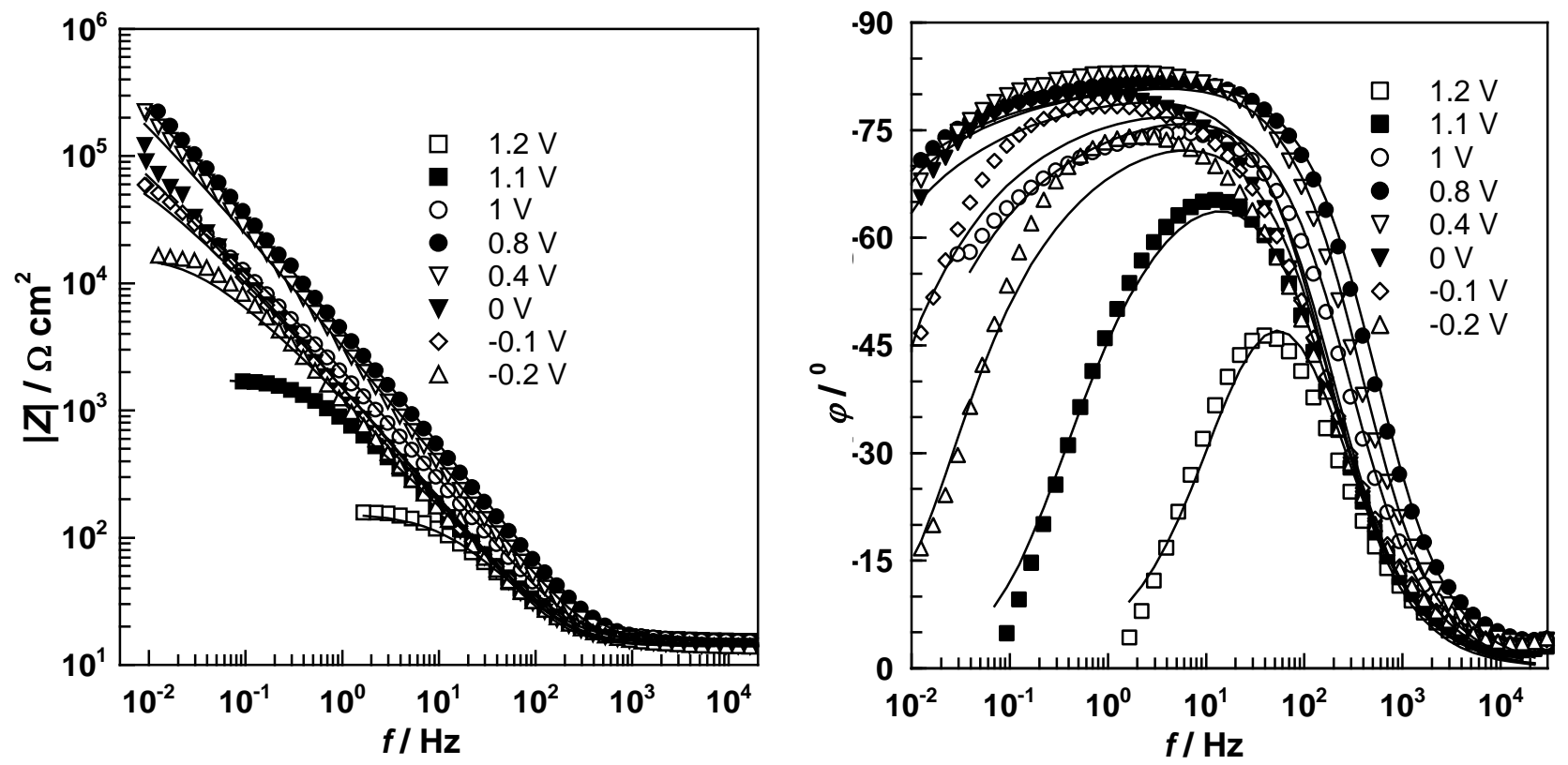

Figure 5. Impedance spectra of $254 \mathrm{SMO}_{\text {in }} 0.5 \mathrm{M} \mathrm{Na}_{2} \mathrm{SO}_{4}, \mathrm{pH} 2$ as a function of potential. Left - impedance magnitude vs. frequency, right - phase angle vs. frequency. Points experimental values, solid lines - best-fit calculation.

The spectra are qualitatively analogous to those obtained earlier for ferritic steels in sulphate solutions [12,14,25-27]. Namely, in the potential region corresponding to the high and almost stable resistance (Figs $1 \mathrm{~b}-3 \mathrm{~b}$ ), the impedance spectra are quasi-independent of potential, showing a predominantly capacitive response, and the impedance magnitude at low frequencies is very high. The phase angle vs. frequency curves are asymmetrical with respect to the maximum phase 
angle, and the phase angle decreases smoothly with decreasing frequency (Fig.5). This shows that the spectra cannot be adequately interpreted using a single time constant involving a constant phase element. At potentials higher and lower than the high-resistance potential region, a decrease of the slope of the magnitude of the impedance vs. frequency dependence is observed (Fig. 5). Simultaneously, the low frequency impedance magnitude decreases and the frequency range in which the spectra have predominantly capacitive character becomes progressively narrower. In other words, the blocking character of the films is diminished and its quasi-steady state conductivity increases.

In order to assess more comprehensively the differences in the behaviour of the studied steels, their impedance spectra are compared in at two characteristic potentials: $-0.2 \mathrm{~V}$ (in the passivation region)and $0.8 \mathrm{~V}$ (at the upper end of the passive region) The spectra at these potentials in the $\mathrm{pH} 2$ solution are shown in Figures 6-7, those measured in the $\mathrm{pH} 4$ solution - in Figures 8-9, and the spectra recorded in the $\mathrm{pH} 7$ solution - in Figs 10-11, respectively.
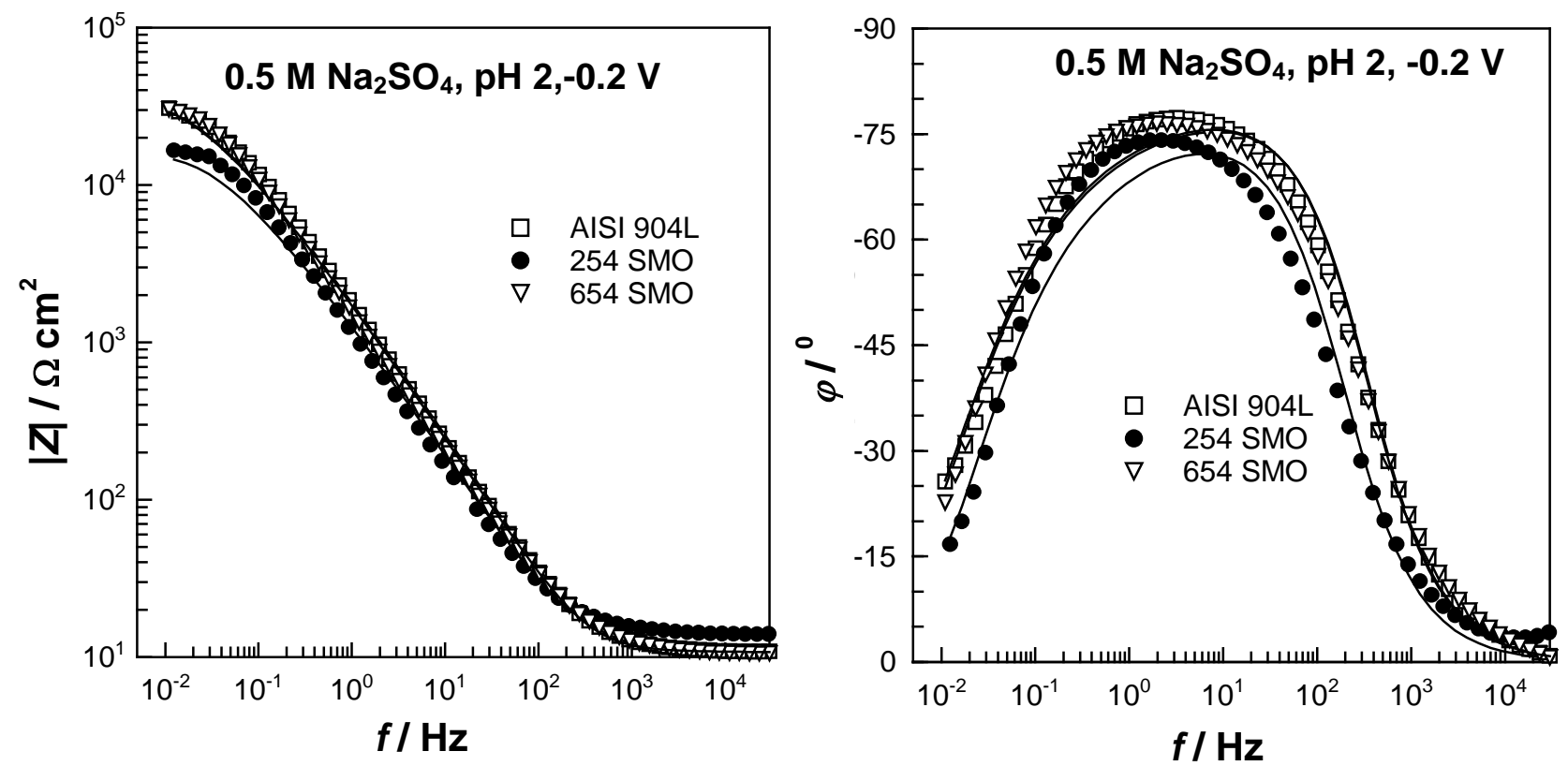

Figure 6. Comparison of the impedance spectra of the studied steels in $0.5 \mathrm{M} \mathrm{Na}_{2} \mathrm{SO}_{4}, \mathrm{pH} 2$ at $0.2 \mathrm{~V}$ (in the passivation region). Left - impedance magnitude vs. frequency, right - phase angle vs. frequency. Points - experimental values, solid lines - best-fit calculation.

In the passivation region (at $-0.2 \mathrm{~V}$ ), the values of the impedance magnitude at low frequencies (e.g. $0.01 \mathrm{~Hz}$ ) are the smallest for $254 \mathrm{SMO}$, the difference between that steel and the two remaining materials being more pronounced at higher $\mathrm{pH}$ (Figs 6, 8 and 10, left columns). In addition, the frequency range in which the phase angle has high and constant values is the narrowest on 254 SMO when compared to the other two steels (Figs 6, 8 and 10, right columns). These observations could be explained by the fact that 254 SMO has the highest amount of Fe (Table 1) which probably dissolves through the film forming in the passive region at the highest rate, which is tantamount of a highest ionic conductivity of the film on this material. On the other hand, the higher amounts of Mo and $\mathrm{Ni}$ in 654SMO and AISI 904L, respectively, could explain the fact that the films formed on these materials in the passivation region are less conductive. Indeed, the differences between the impedances at $0.01 \mathrm{~Hz}$ for $654 \mathrm{SMO}$ and AISI $904 \mathrm{~L}$ at $-0.2 \mathrm{~V}$ are small regardless of the solution $\mathrm{pH}$ (Figs 6, 8 and 10). 

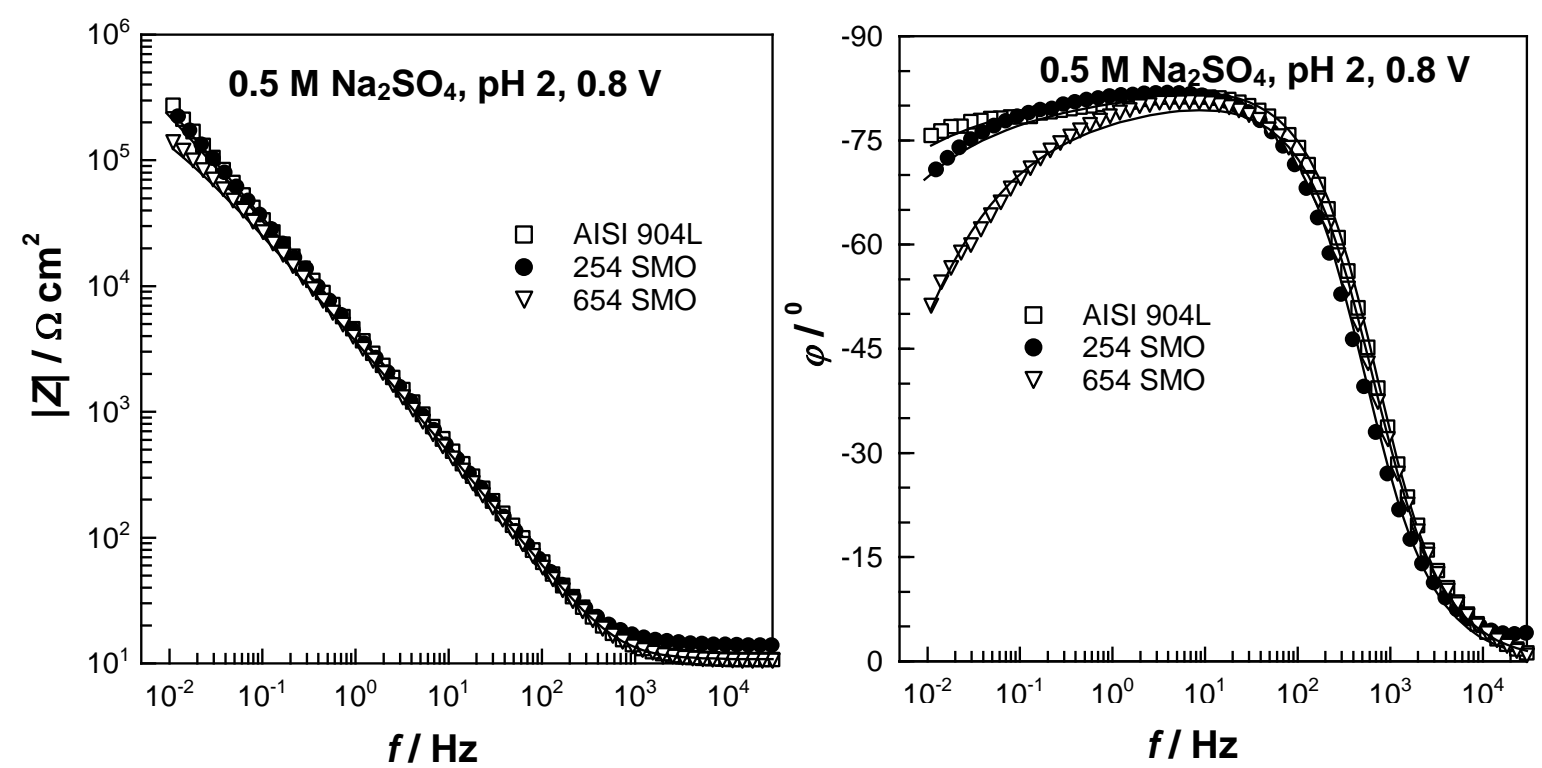

Figure 7. Comparison of the impedance spectra of the studied steels in $0.5 \mathrm{M} \mathrm{Na}_{2} \mathrm{SO}_{4}, \mathrm{pH} 2$ at $0.8 \mathrm{~V}$ (at the upper end of the passive region). Left - impedance magnitude vs. frequency, right - phase angle vs. frequency. Points - experimental values, solid lines - best-fit calculation.
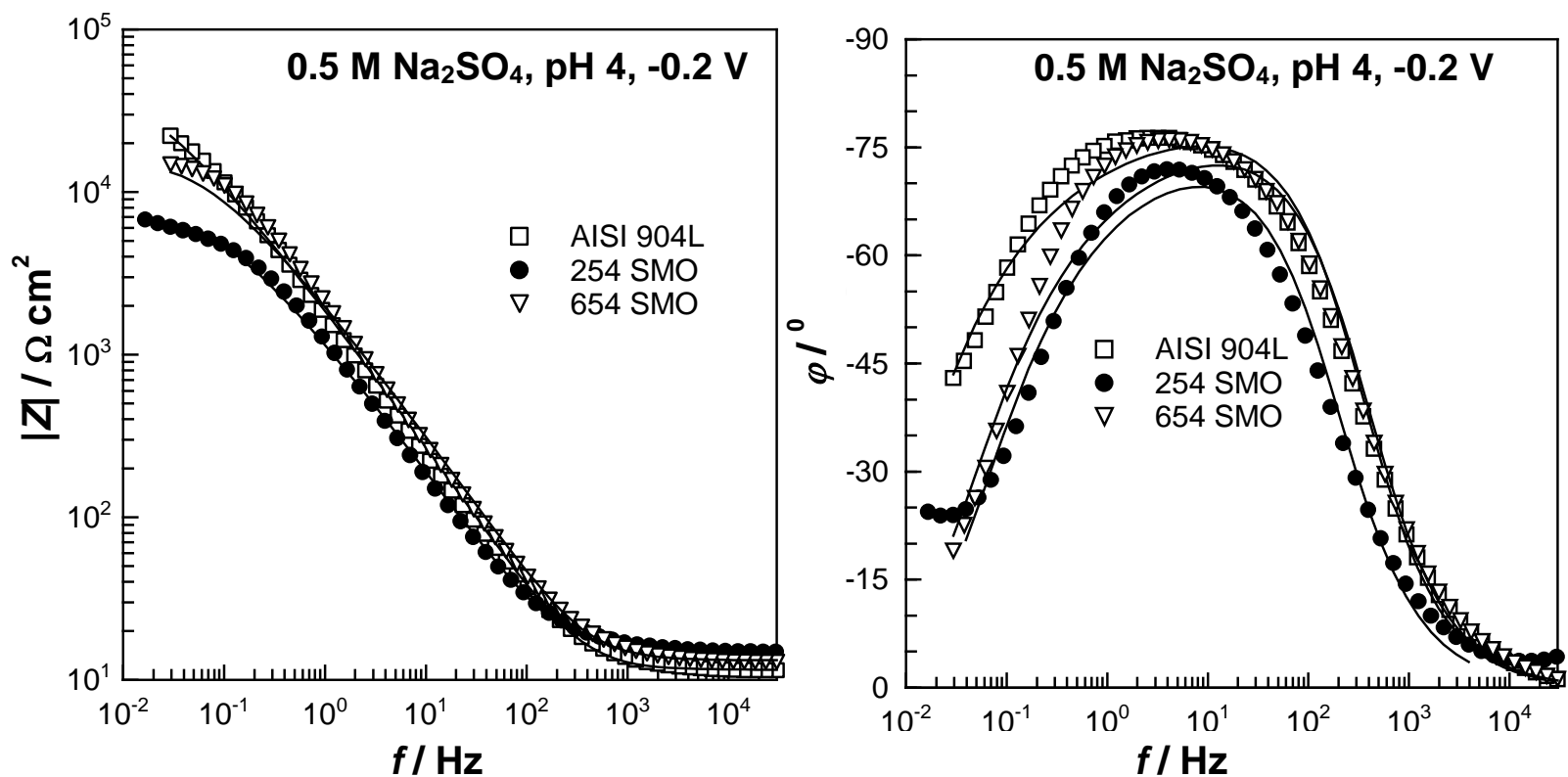

Figure 8. Comparison of the impedance spectra of the studied steels in $0.5 \mathrm{M} \mathrm{Na}_{2} \mathrm{SO}_{4}, \mathrm{pH} 4$ at $0.2 \mathrm{~V}$ (in the passivation region). Left - impedance magnitude vs. frequency, right - phase angle vs. frequency. Points - experimental values, solid lines - best-fit calculation.

In the passive region (at $0.8 \mathrm{~V}$ ), the values of the impedance magnitude at low frequencies (e.g. $0.01 \mathrm{~Hz}$ ) are the smallest for $654 \mathrm{SMO}$ and the greatest for AISI 904L, although the differences are not very significant (Figs 7, 9 and 11, left columns). Further, the impedance magnitude at 0.01 $\mathrm{Hz}$ for $254 \mathrm{SMO}$ and especially for AISI 904L increases slightly with $\mathrm{pH}$, whereas no such effect is noticeable for 654 SMO. Regarding the phase angle curves, it can be stated that in the passive region, the range of frequencies of predominantly capacitive response is the largest for AISI 904L and the smallest for 654 SMO (Figs 7, 9 and 11, right columns). Moreover, for 254 SMO and AISI 904L, the frequency width of the quasi-capacitive impedance increases with pH (Figs 7, 9 and 11, right columns). These observations correlate to a certain extent with the ranking of the impedance magnitude in terms of the blocking character of the passive films. 

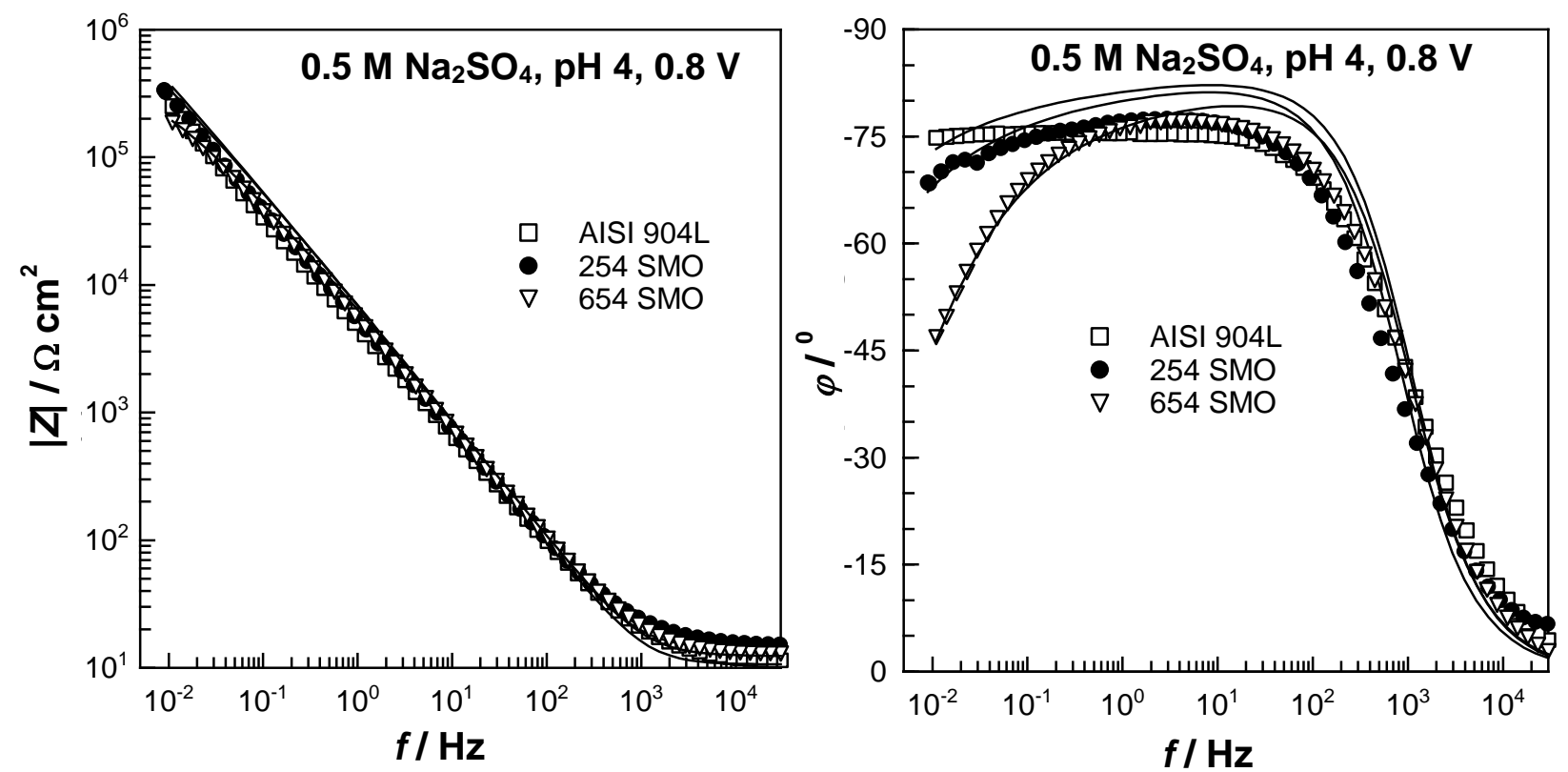

Figure 9. Comparison of the impedance spectra of the studied steels in $0.5 \mathrm{M} \mathrm{Na}_{2} \mathrm{SO}_{4}, \mathrm{pH} 4$ at $0.8 \mathrm{~V}$ (at the upper end of the passive region). Left - impedance magnitude vs. frequency, right phase angle vs. frequency. Points - experimental values, solid lines - best-fit calculation.
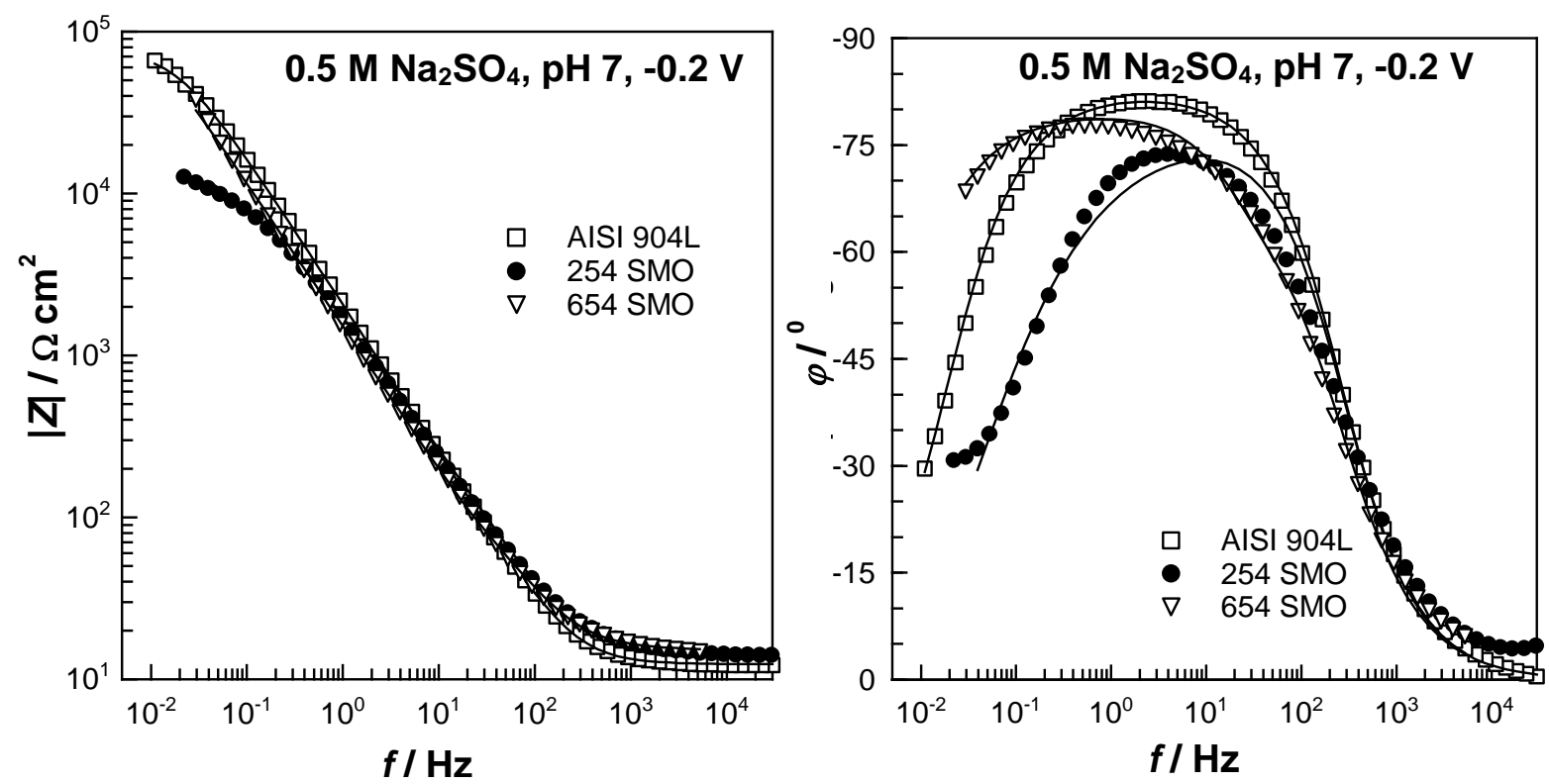

Figure 10. Comparison of the impedance spectra of the studied steels in $0.5 \mathrm{M} \mathrm{Na}_{2} \mathrm{SO}_{4}, \mathrm{pH} 7 \mathrm{at}$ $-0.2 \mathrm{~V}$ (in the passivation region). Left - impedance magnitude vs. frequency, right - phase angle vs. frequency. Points - experimental values, solid lines - best-fit calculation.

Summarising, the impedance spectroscopic results indicate that the small amplitude alternating current response of the studied austenitic steels is qualitatively similar to that ferritic steels as reported previously $[12,14]$. That is, a quasi-capacitive response only slightly affected by potential is found in the passive region, whereas for potentials more negative than this region, enhanced conductivity of the passive films is observed and accordingly their capacitive properties become less perfect. These observations are in accordance to the voltammetric and CER results and point to the occurrence of solid-state redox reactions in the oxide in the active-to-passive transition region. The choice of a proper transfer function to describe the alternating current response based on the MCM and the determination of kinetic, transport and structural parameters for the studied materials is described below. 

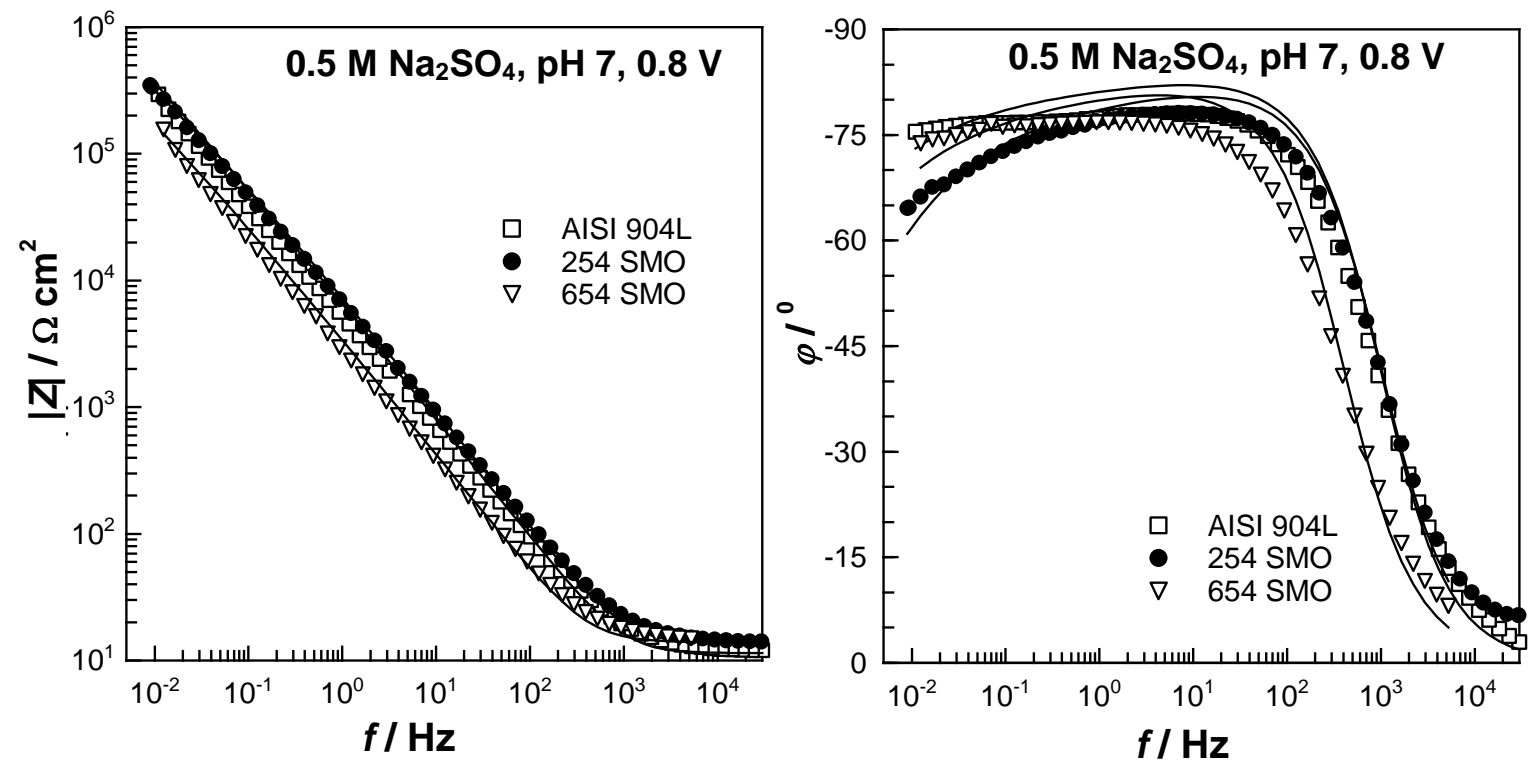

Figure 11. Comparison of the impedance spectra of the studied steels in $0.5 \mathrm{M} \mathrm{Na}_{2} \mathrm{SO}_{4}, \mathrm{pH} 7$ at $0.8 \mathrm{~V}$ (at the upper end of the passive region). Left - impedance magnitude vs. frequency, right phase angle vs. frequency. Points - experimental values, solid lines - best-fit calculation.

\section{Discussion}

\section{Kinetic model}

Both in-situ and ex-situ surface analytical results $[4,16-18,23,28,29]$ have clearly demonstrated that the thickness of the passive films on compatible highly alloyed austenitic steels are in the range of $2-7 \mathrm{~nm}$ and increase linearly with potential in $\mathrm{Na}_{2} \mathrm{SO}_{4}$ solutions ( $\mathrm{pH} 2$ to 7). The passive films have been shown to be based on chromium(III) oxide-hydroxide with a certain amount of $\mathrm{Cr}(\mathrm{VI}), \mathrm{Fe}(\mathrm{II}), \mathrm{Fe}(\mathrm{III}), \mathrm{Ni}(\mathrm{II})$ and some Mo-containing species (probably a mixture of $\mathrm{Mo}(\mathrm{IV})$ and $\mathrm{Mo}(\mathrm{VI}))$ also present [16-18]. The amount of $\mathrm{Fe}$ in the film increases with potential in $\mathrm{Na}_{2} \mathrm{SO}_{4}$ solutions ( $\mathrm{pH} 2$ to 7), which demonstrates that the extent of iron dissolution through the film decreases. This could be correlated to the fact that the higher the potential, the lower the amount of Fe(II) in the passive film. In addition, it has been shown that the higher the content of Mo in the steel, the lower the iron content in the passive film at constant potential [17].

In order to simplify the modelling procedure, it is assumed that the passive film is a single phase oxide based on $\mathrm{Cr}_{2} \mathrm{O}_{3}$ in which $\mathrm{Fe}, \mathrm{Ni}$ and $\mathrm{Mo}$ are treated as substitution defects. The reaction of passive film growth and dissolution is mediated by the generation and consumption of oxygen vacancies

$$
\begin{aligned}
& \mathrm{Cr}_{\mathrm{m}} \longrightarrow \mathrm{Cr}_{\mathrm{Cr}}+1.5 \mathrm{~V}_{\mathrm{O}}^{\cdot \bullet}+3 \mathrm{e}^{\prime} \\
& \mathrm{V}_{\mathrm{O} / \mathrm{F} / \mathrm{F}}^{\bullet} \longrightarrow \mathrm{V}_{\mathrm{O} / \mathrm{s}}^{\cdot \bullet} \\
& 1.5 \mathrm{~V}_{\mathrm{O} \mathrm{F} / \mathrm{s}}^{\bullet}+1.5 \mathrm{H}_{2} \mathrm{O} \longrightarrow 1.5 \mathrm{O}_{\mathrm{O}}+3 \mathrm{H}^{+} \\
& 0.5 \mathrm{Cr}_{2} \mathrm{O}_{3}+3 \mathrm{H}^{+} \longrightarrow \mathrm{Cr}^{3+}+1.5 \mathrm{H}_{2} \mathrm{O}
\end{aligned}
$$

This reaction does play a comparatively minor role in determining the steady-state and small amplitude alternating current response. This assumption is supported by electrochemical quartz microbalance measurements on comparable steels of Olsson and Landolt [30,31]. It has been shown by these authors that during a potential step, the fraction of cations formed at the metal|oxide interface that dissolve at the film / solution interface is between 0.66 and 0.84 , i.e. the 
main processes are related to the dissolution of cations through the oxide and not to film formation. In other words, at the steady state, both the current density and the impedance response are assumed to be mainly determined by the reactions of metal dissolution through the film ("corrosion") mediated by the generation, transport and consumption of point defects in the cation sub-lattice (interstitial cations and cation vacancies).

The dissolution of Fe through the passive film is expressed as the combination of the generation of interstitial Fe cations of formal valence $\chi$ (between 2 and 3 ) at the metal|film (M|F) interface, their transport through the film and their oxidative dissolution at the film/solution (F|S) interface

$$
\begin{aligned}
& \mathrm{Fe}_{\mathrm{m}} \stackrel{k_{1 i}}{\longrightarrow} \mathrm{Fe}_{\mathrm{i}}^{\chi^{\bullet}}{ }_{\mathrm{MlF}}+\chi \mathrm{e}^{\prime} \\
& \mathrm{Fe}_{\mathrm{i}}^{\chi^{\bullet} \mathrm{MIF}} \stackrel{D_{\mathrm{i}}, \mathrm{E}}{\longrightarrow} \mathrm{Fe}_{\mathrm{i}}^{\chi^{\bullet} \mathrm{FlS}} \\
& \mathrm{Fe}_{\mathrm{i} \text { FIS }}^{\chi^{\bullet}} \stackrel{k_{3 i}}{\longrightarrow} \mathrm{Fe}_{\mathrm{aq}}^{\mathrm{y}+}+(\mathrm{y}-\chi) \mathrm{e}^{\prime}
\end{aligned}
$$

The fact that passive films on stainless steels contain iron in an oxidation state lower than III has been demonstrated by XPS [16-18, 29].

On the other hand, the dissolution of $\mathrm{Cr}$ through the film to generate soluble $\mathrm{Cr}(\mathrm{VI})$ is mediated by the generation of $\mathrm{Cr}$ cation vacancies at the F/S interface via oxidative dissolution of $\mathrm{Cr}$ (III), their transport through the film and their consumption at the M|F interface

$$
\begin{aligned}
& \mathrm{Cr}_{\mathrm{Cr}}^{\prime \prime \prime} \stackrel{k_{3}}{\longrightarrow} \mathrm{Cr}_{\mathrm{aq}}^{6+}+\mathrm{V}_{\mathrm{CrF} \mid \mathrm{S}}^{\prime \prime \prime}+3 \mathrm{e}^{\prime} \\
& \mathrm{V}_{\mathrm{CrF} \mid \mathrm{S}}^{\prime \prime} \stackrel{D_{\mathrm{V}}, \mathrm{E}}{\longrightarrow} \mathrm{V}_{\mathrm{CrM} \mid \mathrm{F}}^{\prime \prime} \\
& \mathrm{Cr}_{\mathrm{m}}+\mathrm{V}_{\mathrm{CrM} \mid \mathrm{F}} \stackrel{k_{1}}{\longrightarrow} \mathrm{Cr}_{\mathrm{Cr}}^{\prime \prime \prime}+3 \mathrm{e}^{\prime}
\end{aligned}
$$

It can be in principle postulated that the dissolution of Mo through the film follows the same route as that of $\mathrm{Cr}$, although at low potentials in the passivation region, the dissolution of Mo via the interstitial route probably cannot be neglected.

At difference to the film formation-dissolution sequence (1), the sequences of reactions (2) and (3) leading to cation dissolution through the film contain charge transfer steps at both the alloy|film and film/solution interfaces. Thus it is expected that a discrimination between the contributions of the film growth-dissolution, on one hand, and the metal dissolution through the film, on the other, can be achieved by analysing the dependence of the steady-state current and the impedance response on the applied potential.

The rate constants are thought to obey an exponential dependence on the potential drops at the appropriate interfaces: $k_{\mathrm{j}}=k_{\mathrm{j}}^{0} \exp \left(b_{\mathrm{j}} \phi_{\mathrm{N}}\right)$, where $j=1,1 i, 3,3 i, \mathrm{~N}=\mathrm{M}|\mathrm{F}, \mathrm{F}| \mathrm{S}, k_{\mathrm{j}}^{0}$ is a standard rate constant and $b_{\mathrm{j}}=\alpha_{\mathrm{j}} F / R T$ is a Tafel coefficient. Strictly speaking, the potential needs to be expressed vs. the equilibrium potential of the $\mathrm{Cr}_{2} \mathrm{O}_{3} / \mathrm{Cr}$ redox couple at each $\mathrm{pH}$. Thus in what follows, the values of the standard rate constants will be expressed vs. this equilibrium potential. The transport of point defects is proposed to obey a high-field conduction equation of the type (written for interstitial cations as an example)

$$
J_{i}(x, t)=-0.5\left[D_{\mathrm{i}} \frac{\partial c_{\mathrm{i}}(x, t)}{\partial \mathrm{x}}+\frac{D_{\mathrm{i}}}{a} c_{\mathrm{i}}(x, t)\right] \exp \left[\frac{2 F a E(x, t)}{R T}\right]
$$

where $J_{\mathrm{i}}(x, t)$ is the instantaneous flux of interstitial cations, $c_{\mathrm{i}}(x, t)$ is their instantaneous concentration, $D_{\mathrm{i}}$ - their diffusion coefficient, $a$ is the half-jump distance for hopping transport and $\boldsymbol{E}(x, t)$ is the instantaneous field strength. 
The applied potential is assumed to be distributed as potential drops at the interfaces ( $\phi_{M \mid F}$ and $\left.\phi_{F \mid S}\right)$ and in the bulk film according to the PDM and MCM [8-14]

$$
E=\phi_{M \mid F}+E L+\phi_{F \mid S}
$$

As demonstrated for compatible stainless steels in comparable media $[16,18,28,30]$ the steadystate film thickness $L$ depends linearly on potential $E$ (i.e. the field strength in the passive film is independent on potential and distance)

$$
\bar{L}=\bar{L}_{E=0}+\frac{(1-\alpha) E}{\boldsymbol{E}}
$$

In the above equation, $\alpha$ is the part of the potential consumed as drop at the $F / S$ interface and $\boldsymbol{E}$ is the field strength. It follows from (5) and (6) that the steady-state potential drop at the M|F interface is independent of the applied potential. In such a case, only the dependences of the reaction rate constants at the film/solution interface on potential need to be considered $[12,14,24]$.

The expression for the steady-current density vs. potential dependence can be obtained in terms of the PDM and MCM [8-14] and also related approaches [32]. According to the above assumptions, the steady-state current density $(\bar{i})$ is the sum of the partial current densities due to the reaction sequences (2) and (3)

$$
\bar{i}=\chi F D_{\mathrm{i}}^{\prime} \bar{c}_{\mathrm{i}}(L)+3 F D_{\mathrm{v}}^{\prime} \bar{c}_{\mathrm{v}}(L)
$$

where

$$
\begin{aligned}
& \bar{c}_{\mathrm{i}}(L)=k_{1 \mathrm{i}}\left[k_{3 \mathrm{i}}{ }^{-1} \exp \left(-\frac{\bar{L}}{a}\right)+\frac{a}{D_{\mathrm{i}}^{\prime}}\right] \\
& \bar{c}_{V}(L)=\frac{k_{3}}{k_{1}}
\end{aligned}
$$

and

$$
D_{\mathrm{i}}^{\prime}=\frac{1}{2} D_{\mathrm{i}} e^{\frac{\chi F a E}{R T}}, D_{\mathrm{v}}^{\prime}=\frac{1}{2} D_{\mathrm{v}} e^{\frac{3 F a E}{R T}}
$$

are the apparent (field-dependent) diffusion coefficients of interstitial cations and cation vacancies, and $D_{v}$ the vacancy diffusion coefficient. Inserting (8) and (9) in (7) the following expression for the steady-state current density is obtained

$$
\bar{I}=\frac{\chi F D_{i}^{\prime}}{a} \frac{k_{1 i}^{0}}{k_{3 i}^{0}} e^{-b_{3 i} \alpha E} e^{-\frac{\bar{L}}{a}}+2 F k_{1 i}^{0}+\frac{3 F D^{\prime}}{a} \frac{k_{3}^{0}}{k_{1}^{0}} e^{b_{3} \alpha E}
$$

It is worth mentioning that the steady-state current density is a function of both the apparent diffusion coefficients and the rate constants of the interfacial rreactions, i.e. the processes in the metal|film/solution system are both reaction and transport controlled.

The impedance response of the film can be given as the sum of the impedances due to electronic properties of the film $\left(Z_{e}\right)$ and ionic transport through it $\left(R_{\text {ion }}\right)$ in parallel:

$$
Z_{\mathrm{f}}=\left(Z_{\mathrm{e}}^{-1}+R_{\mathrm{ion}}^{-1}\right)^{-1}
$$


The validity of this equation for a film exhibiting both ionic and electronic conduction, with the principal ionic current carriers playing the role of electron donors or acceptors, could in principle be questioned because of the anticipated coupling between the ionic and electronic fluxes. However, during impedance measurements in electrolytes that do not contain redox couples, as in the present investigation, the electronic current carriers are blocked at the film/solution interface and in fact contribute to the capacitive charging current of the depletion layer in the semiconducting oxide, whereas the faradaic current is due to the transport of ionic point defects alone [15]. This justifies the use of equation (12) in the present experimental conditions. The transfer function (equation (12)) can account for the small amplitude alternating current response of the passive alloys provided that the interfacial impedances are negligible with respect to the impedance of the film.

Considering the ability of the ionic point defects to act as electron donors or acceptors [8-15] gives the possibility to express the impedance due to the electronic properties of the film in the form $[12,14,33]$

$$
Z_{\mathrm{e}}=\frac{p}{j \omega C} \ln \frac{1+\mathrm{j} \omega \rho_{\mathrm{d}} \varepsilon \varepsilon_{0} \mathrm{e}^{1 / p}}{1+\mathrm{j} \omega \rho_{\mathrm{d}} \varepsilon \varepsilon_{0}}
$$

where

$$
\begin{aligned}
& p^{-1}=\frac{\bar{L}}{a} \\
& \rho_{\mathrm{d}}^{-1}=\frac{F^{2} D_{\mathrm{e}}}{R T}\left(\frac{k_{3}^{0}}{k_{1}^{0}} e^{b_{3} \alpha E}+\frac{k_{1 \mathrm{i}}^{0}}{k_{3 \mathrm{i}}^{0}} e^{-b_{3 i} \alpha E}\right)
\end{aligned}
$$

$C$ is the capacitance of the space charge layer, $D_{\mathrm{e}}$ is the diffusion coefficient of electronic current carriers, $\varepsilon$ is the dielectric constant of the oxide and $\varepsilon_{0}$ the dielectric permittivity of free space.

This type of impedance can be regarded as the impedance of a semiconductor film in which the defect densities are a function of both the potential and the distance within the film. It is worth noticing that a frequency dispersion of the impedance components consistent with such an expression has been already reported for similar steels in comparable media [34].

As no Warburg impedance has been identified in the experimental spectra (Figs 2-10), the impedance of ionic transport is proposed to reduce to a migration resistance $R_{\text {ion }}[12,14,32]$ :

$$
R_{i o n}^{-1}=\frac{(\chi F)^{2} D_{i}^{\prime}}{R T a}(1-\alpha) \frac{k_{1 \mathrm{i}}^{0}}{k_{3 \mathrm{i}}^{0}} e^{-b_{3 i} \alpha E} e^{-\frac{\bar{L}}{a}}+\frac{(\chi F)^{2}}{R T}(1-\alpha) k_{1 \mathrm{i}}^{\prime 0}+\frac{9 F^{2} D^{\prime}{ }_{\mathrm{V}}}{R T a}(1-\alpha) \frac{k_{3}^{0}}{k_{1}^{0}} e^{b_{3} \alpha E}
$$

Once again, it is stressed that the ionic transport resistance depends not only on the diffusion coefficients and field strength in the oxide, but also on the rate constants of the interfacial reactions.

Summarising, we intend to describe both the steady state and the impedance response of the studied passive alloys in terms of four interfacial reactions $\left(k_{1}, k_{1 i}, k_{3}, k_{3 i}\right)$, the rates of two of which (at the film/solution interface) are dependent on the applied potential (exponential coefficients $b_{3}$ and $b_{3 i}$ multiplied by the part of the potential consumed as a drop at the film/solution interface $\alpha)$, three diffusion coefficients $\left(D_{\mathrm{i}}, D_{\mathrm{V}}\right.$ and $D_{\mathrm{e}}$ for interstitial cations, cation vacancies and electronic carriers), the half-jump distance for high-field transport, $a$, the field strength in the film, $\boldsymbol{E}$, and its dielectric permittivity, $\varepsilon$. 


\section{Comparison with experimental data}

As a first step in such a comparison, the extensive set of impedance data for the three materials in the three electrolyte solutions were fitted using the transfer function defined by equations (12), (13) and (17). In other words, every individual impedance spectrum is described by four parameters: $C, p, \rho_{\mathrm{d}} \varepsilon$ and $R_{\text {ion }}$ in addition to the resistance of the electrolyte. The calculated spectra are shown in Figs 5-11 with solid lines and demonstrate the ability of such a transfer function to account for the experimental data. The values of the parameters $C, p, \rho_{\mathrm{d}} \varepsilon$ and $R_{\text {ion }}$ together with the steady-state current density are plotted in Figs 12-14 as a function of potential.
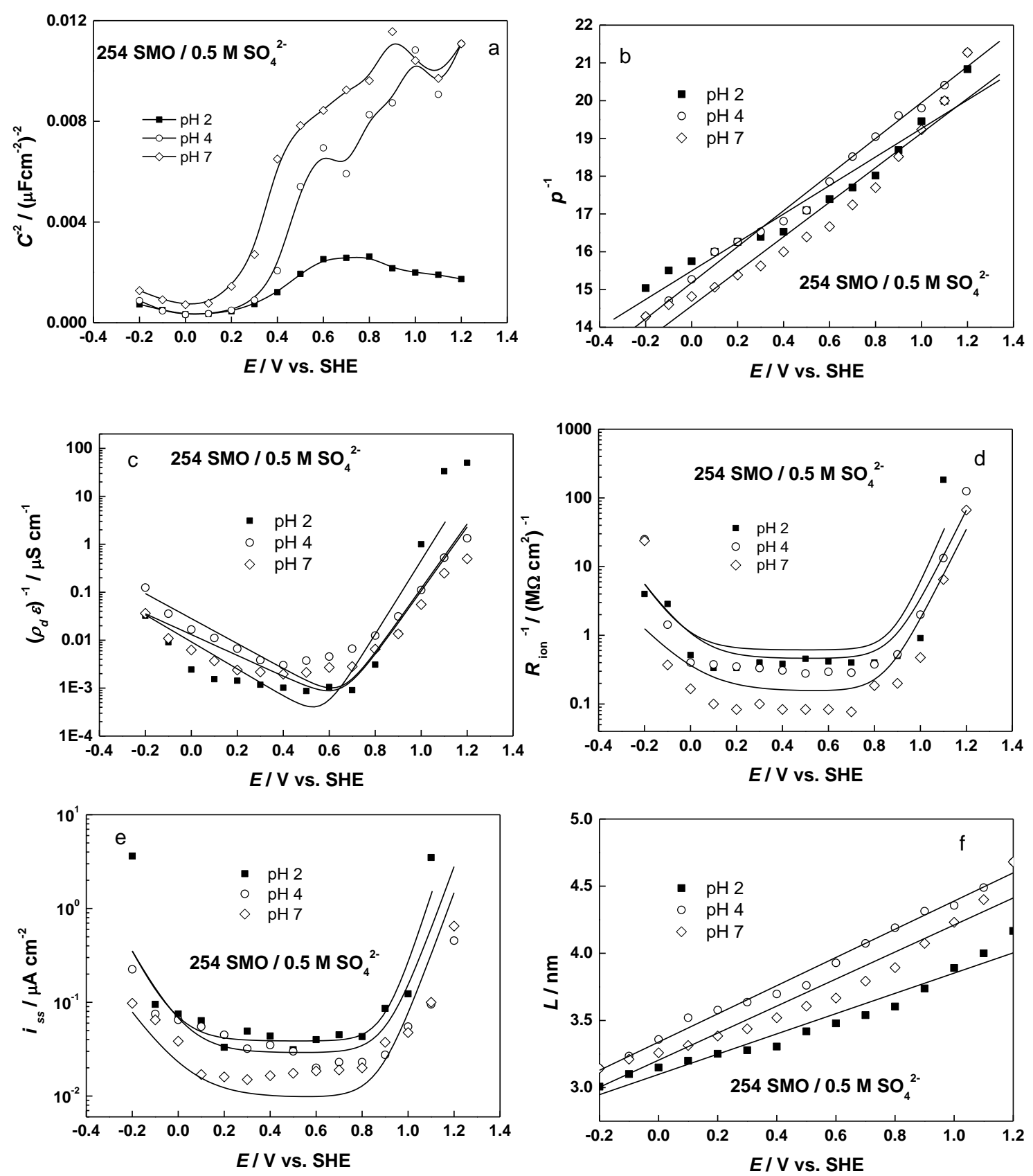

Figure 12. Dependence of the steady state current density and the parameters of the transfer function on potential and $\mathrm{pH}$ for $254 \mathrm{SMO}$ in $0.5 \mathrm{M} \mathrm{Na}_{2} \mathrm{SO}_{4}$ : (a) film capacitance, $\mathrm{C}$;

(b) relative depth of penetration of the conductivity profile, $p$; (c) product of the defect induced interfacial resistivity and the dielectric constant of the film, $\left(\rho_{d} \varepsilon\right)^{-1} ;(d)$ resistance of migration of ionic point defects, $\mathrm{R}_{\mathrm{ion}}$ ( (e) steady-state current density, $\mathrm{i}_{\mathrm{s} s}$. $(\mathrm{f})$ steady-state thickness, $L$.

The solid lines in (b)-(e) are predicted by the corresponding equations of the MCM. 
The capacitance of the passive film plotted in Mott-Schottky coordinates $\left(C^{-2}\right.$ vs. applied potential) in general decreases with potential in the passive region (Figs 12a, 13a, 14a), demonstrating an apparent n-type semiconductor behaviour in accordance to previous capacitance and photo-electrochemical measurements on compatible steels [35-38]. Such a behaviour of the capacitance is consistent with interstitial cations being the dominant ionic current carriers acting as electron donors [9]. The $C^{-2}$ vs. $E$ curves are not linear, however, indicating that the donor density is dependent on potential and/or distance within the film. It is worth noting that the capacitance values are the smaller, the higher the $\mathrm{pH}$ of the solution. This can be associated with a decrease of the dielectric constant of the films with increasing $\mathrm{pH}$ and correlated to the variation of the oxide composition and/or thickness with $\mathrm{pH}$.
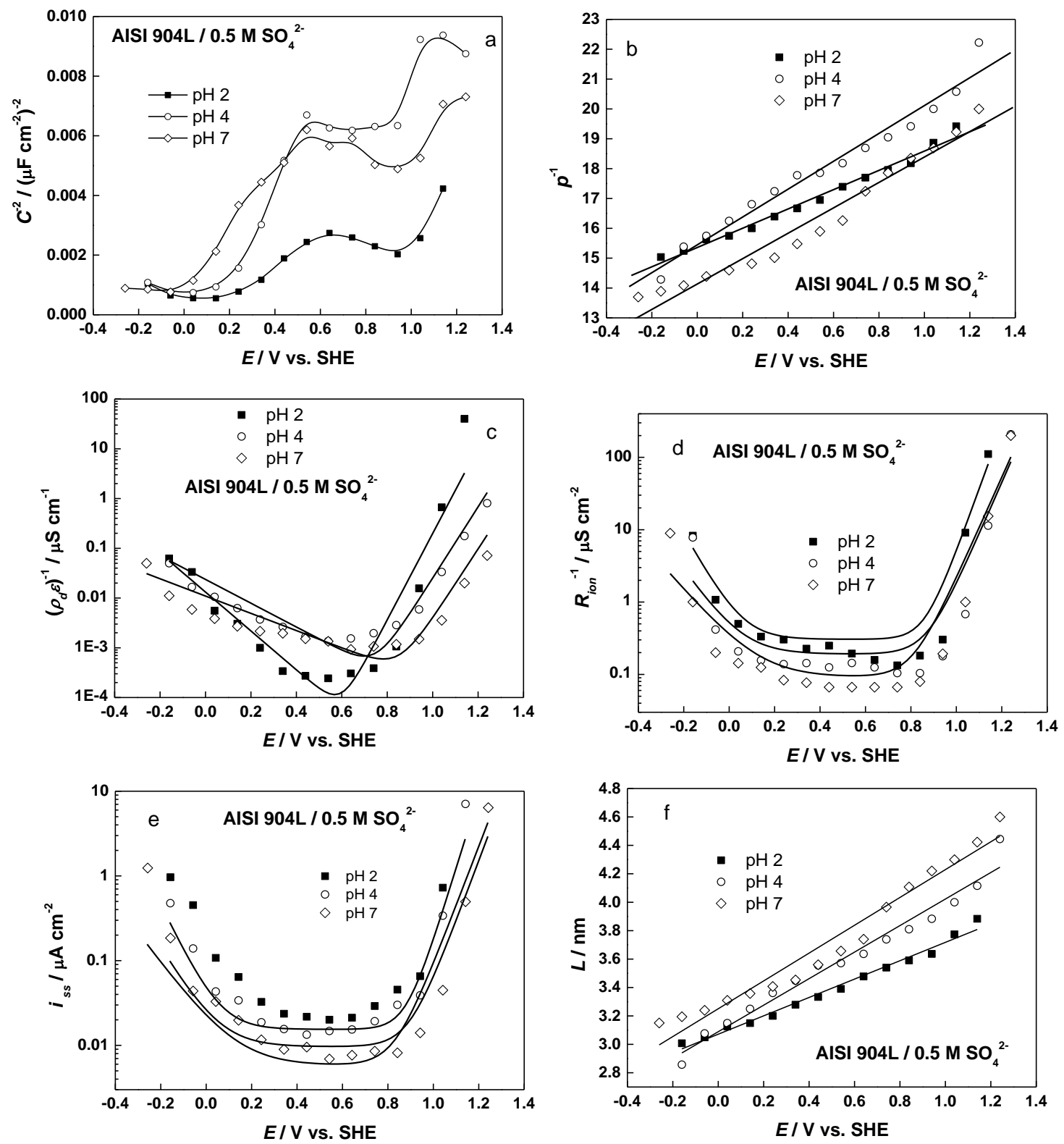

Figure 13. Dependence of the steady state current density and the parameters of the transfer function used to fit the impedance data on potential and pH for AISI $904 \mathrm{~L}$ in $0.5 \mathrm{M} \mathrm{Na}_{2} \mathrm{SO}_{4}$ : (a) film capacitance, $\mathrm{C}$;

(b) relative depth of penetration of the conductivity profile, $p$; (c) product of the defect induced interfacial resistivity and the dielectric constant of the film, $\left(\rho_{d} \varepsilon\right)^{-1} ;(d)$ resistance of migration of ionic point defects, $R_{\text {ion; }}(\boldsymbol{e})$ steady-state current density, $i_{s s}(f)$ steady-state thickness, $L$.

The solid lines in (b)-(e) are predicted by the corresponding equations of the MCM. 

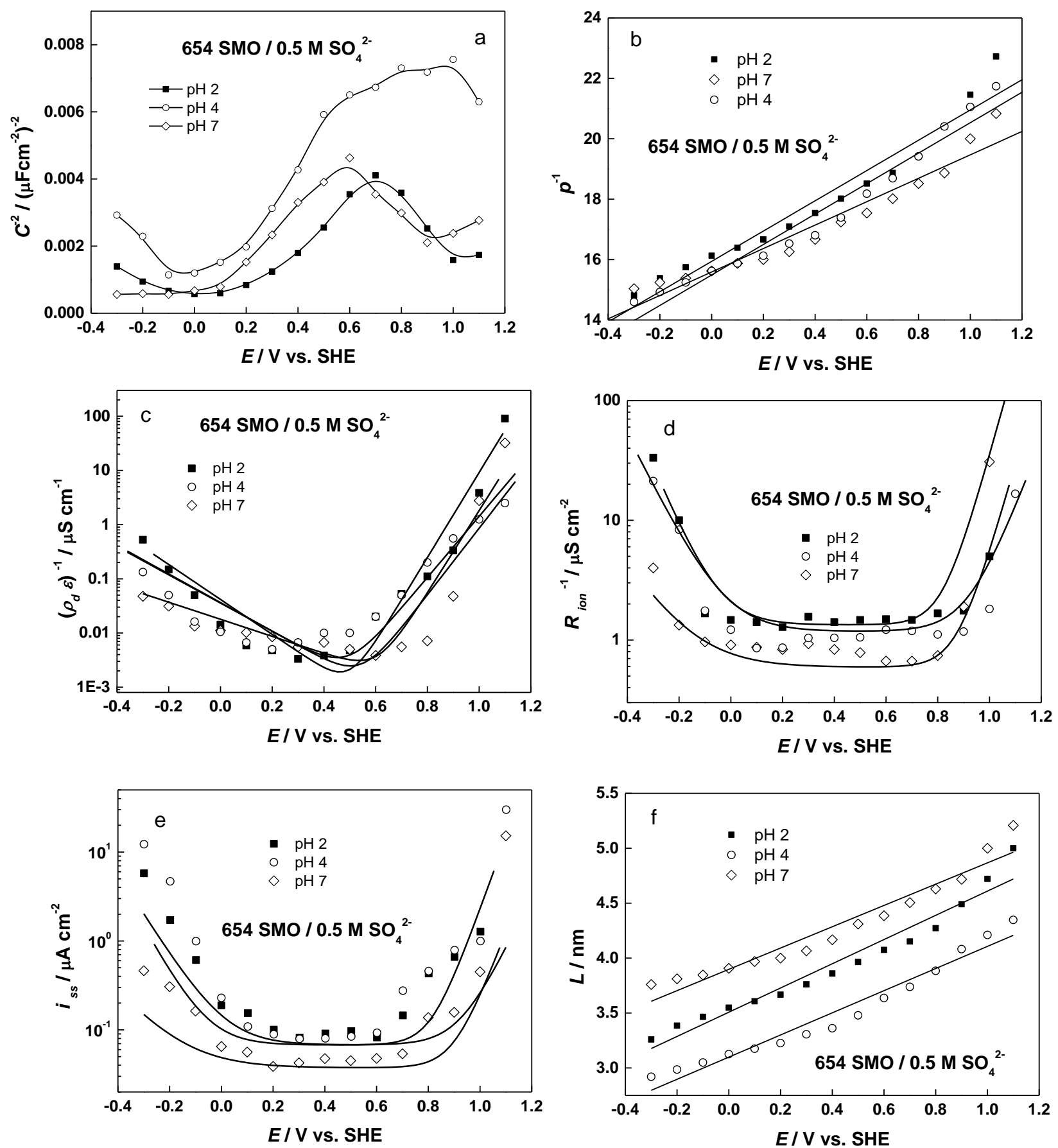

Figure 14. Dependence of the steady state current density and the parameters of the transfer function used

to fit the impedance data on potential and $\mathrm{pH}$ for $654 \mathrm{SMO}_{\text {in }} 0.5 \mathrm{M} \mathrm{Na}_{2} \mathrm{SO}_{4}$ : (a) film capacitance, $\mathrm{C}$;

(b) relative depth of penetration of the conductivity profile, $p$; (c) product of the defect induced interfacial resistivity and the dielectric constant of the film, $\left(\rho_{d} \varepsilon\right)^{-1} ;(d)$ resistance of migration of ionic point defects,

$R_{\text {ion; }}(\boldsymbol{e})$ steady-state current density, $i_{s s}(f)$ steady-state thickness, $L$.

The solid lines in (b)-(e) are predicted by the corresponding equations of the MCM.

As a next step in the comparison of the model to the experimental data, the $p^{-1},\left(\rho_{\mathrm{d}} \varepsilon\right)^{-1}$ and $R_{\text {ion }}{ }^{-1}$ $v s$. potential dependences together with the dependence of the steady-state current density on potential for a particular material-electrolyte combination have been simultaneously fitted to the model equations (11), (14), (15) and (17). Statistical weighting was used for the experimental data set and the errors of parameter estimation were multiplied by the square root of the reduced chisquare value resulting from the fit. The fitting was performed so that kinetic parameters that 
showed a mutual dependency higher than 0.7 have never been set free simultaneously. The goodness of fit as judged by the $R^{2}$ and chi-square values was deemed acceptable, taking into account the large difference in magnitude of both the fitted functions and the kinetic parameters. Of course, the large amount of kinetic parameters does not in principle exclude the possibility of the fitting procedure to converge to a local minimum. However, taking into account the statistical validity of the fitting results, such a possibility is considered remote.

The best-fit results are shown in Figs 12(b-e) - 14(b-e) with solid lines and demonstrate the ability of the model to reproduce both the general shape of the dependencies of the parameters on potential and the absolute values of the parameters. This can be taken as a proof for the ability of the model to predict both the steady-state and small amplitude alternating current response of the studied materials in a wide potential and $\mathrm{pH}$ range.

The estimates of the kinetic parameters for the three steels in the three electrolyte solutions are collected in Table 2 (254 SMO), Table 3 (AISI 904L) and Table 4 (654 SMO), respectively. As mentioned above, the values of the standard rate constants of the reactions at the film/solution interface are given vs. the equilibrium potential of the $\mathrm{Cr}_{2} \mathrm{O}_{3} / \mathrm{Cr}$ couple taken from the respective E-pH diagram $(0.058 \mathrm{~V}$ at $\mathrm{pH} 2,-0.300 \mathrm{~V}$ at $\mathrm{pH} 4$ and $-0.83 \mathrm{~V}$ at $\mathrm{pH} 7$, respectively). The overall set of parameters can be classified as homogeneous, especially concerning the exponential coefficients of the kinetic steps at the film/solution interface $b_{3}$ and $b_{3 i}$ and the transport parameters (diffusion coefficients and half-jump distances). This is perhaps not surprising taking into account the relatively small differences in the impedance spectra of the studied alloys, but demonstrates once again the stability of the calculation procedure.

Table 2. Kinetic parameters for the passive film on $254 \mathrm{SMO}$ formed in $0.5 \mathrm{M} \mathrm{Na}_{2} \mathrm{SO}_{4}$ solutions of $\mathrm{pH} 2,4$ and 7.

\begin{tabular}{|l|c|c|c|}
\hline Parameter & $\mathrm{pH} 2$ & $\mathrm{pH} 4$ & $\mathrm{pH} 7$ \\
\hline$k_{1}{ }^{0} / \mathrm{mol} \mathrm{cm}^{-2} \mathrm{~s}^{-1}$ & $2.5 \times 10^{-9}$ & $2.1 \times 10^{-9}$ & $7.0 \times 10^{-9}$ \\
\hline$k_{1 \mathrm{i}}{ }^{0} / \mathrm{mol} \mathrm{cm}^{-2} \mathrm{~s}^{-1}$ & $2.0 \times 10^{-13}$ & $1.5 \times 10^{-13}$ & $0.5 \times 10^{-13}$ \\
\hline$k_{3}{ }^{0} / \mathrm{mol} \mathrm{cm}^{-2} \mathrm{~s}^{-1}$ & $3.3 \times 10^{-19}$ & $1.1 \times 10^{-21}$ & $3.7 \times 10^{-26}$ \\
\hline$k_{3 \mathrm{i}}{ }^{0} / \mathrm{mol} \mathrm{cm}^{-2} \mathrm{~s}^{-1}$ & $6.0 \times 10^{-9}$ & $3.3 \times 10^{-10}$ & $7.7 \times 10^{-11}$ \\
\hline$\alpha b_{3} / \mathrm{V}^{-1}$ & 17.7 & 15.5 & 15.3 \\
\hline$\alpha b_{3 \mathrm{i}} / \mathrm{V}^{-1}$ & 6.5 & 6 & 5 \\
\hline$D_{\mathrm{e}} / \mathrm{cm}^{2} \mathrm{~s}^{-1}$ & $2.5 \times 10^{-9}$ & $3.0 \times 10^{-9}$ & $5.0 \times 10^{-9}$ \\
\hline$D_{\mathrm{i}} / \mathrm{cm}^{2} \mathrm{~s}^{-1}$ & $1.0 \times 10^{-14}$ & $1.4 \times 10^{-14}$ & $0.9 \times 10^{-14}$ \\
\hline$D_{\mathrm{V}} / \mathrm{cm}^{2} \mathrm{~s}^{-1}$ & $0.67 \times 10^{-17}$ & $3.0 \times 10^{-17}$ & $6.0 \times 10^{-17}$ \\
\hline$a / \mathrm{cm}^{-17}$ & $2.0 \times 10^{-8}$ & $2.2 \times 10^{-8}$ & $2.2 \times 10^{-8}$ \\
\hline$\varepsilon$ & 50 & 30 & 15 \\
\hline$\alpha$ & 0.78 & 0.78 & 0.78 \\
\hline$E / \mathrm{V} \mathrm{cm}$ & $3.0 \times 10^{6}$ & $2.5 \times 10^{6}$ & $3.0 \times 10^{6}$ \\
\hline
\end{tabular}

The following conclusions can be drawn from a comparison of the parameter values for the studied steels in the corresponding electrolyte solutions:

The rate constants of the reactions at the alloy|film interface in general decrease with increasing $\mathrm{pH}$, the effect being altogether not very significant (within an order of magnitude). It can be stated that the rate constant of consumption of cation vacancies is far higher than that of generation of interstitial cations, the difference being the highest for 654 SMO. The values are in fair agreement with those obtained earlier for ferritic steels in a borate solution [15]. As the Fe 
content in the inner layers of the passive film is much smaller than the $\mathrm{Cr}$ content, and bearing in mind that there is probably $\mathrm{Ni}$ enrichment at the alloy|film interface beneath the passive film $[16,18]$, such a difference can be understood by regarding the alloy/film interface as a contact between a metallic phase enriched in $\mathrm{Ni}$ and a film based mainly on $\mathrm{Cr}_{2} \mathrm{O}_{3}$ (which is in principle expected to exchange mainly cation vacancies with the underlying metal). As the rate of transpassive dissolution of $\mathrm{Cr}$ in the most part of the passive range is very low, and the concentration of divalent Fe is rather small [23], it follows from equation (6) that the steady-state current density, or the metal dissolution rate, is controlled by the $k_{1 i}$ step. The rate constant of this step is the smallest for AISI904L (Tables 2-4), which correlates well with the smallest passive current densities and steady-state ionic conductivities $\left(R_{\text {ion }}{ }^{-1}\right)$ for this alloy (Figs $14(\mathrm{~d}-\mathrm{e})$-16(d-e)). It is tempting to relate this feature to the fact that AISI $904 \mathrm{~L}$ has the highest Ni content of all the studied materials (Table 1 ). The somewhat surprising fact that the highest values of $k_{1 \mathrm{i}}$ (and accordingly, the highest passive current densities and steady-state ionic conductivities) are measured for $654 \mathrm{SMO}$ can be tentatively related to the highest amount of Mo in this alloy when compared to the other two materials. In that connection, it has been reported that the dissolution rates of Mo-containing ferritic and austenitic stainless steels in the passive state are higher than those for the steels without Mo $[30,40]$.The values of the rate constant of oxidative dissolution of interstitial cations at the film/solution interface, $k_{3 i}{ }^{0}$, is many orders of magnitude higher than that of the oxidative dissolution of $\mathrm{Cr}$ ( $k_{3}$ step) which is also in accordance to the suggestion that the main path for dissolution in the passive state is the interstitial path. On the other hand, the exponential coefficient of this step, $b_{3 \mathrm{i}}$ is ca. 3 times smaller than that of $b_{3}$, i.e. at sufficiently high potentials the transpassive dissolution is expected to start dominating, as observed experimentally. The values of the standard rate constants of both reactions decrease significantly with increasing $\mathrm{pH}$, indicating a decrease of the rate of ejection of cations at that interface and hence the dissolution rate of Fe through the passive film. The rate constant $k_{3 i}{ }^{0}$ is the smallest for AISI 904L and the largest for 654 SMO (Tables 2-4), whereas the values of $k_{3}{ }^{0}$ are the highest for $654 \mathrm{SMO}$, i.e. correlate with the highest concentration of $\mathrm{Cr}$ and $\mathrm{Mo}$ in the alloy which should render it the most susceptible to transpasssive dissolution.

Table 3. Kinetic parameters for the passive film on AISI $904 \mathrm{~L}$ formed in $0.5 \mathrm{M} \mathrm{Na}_{2} \mathrm{SO}_{4}$ solutions of $\mathrm{pH} \mathrm{2,} 4$ and 7 .

\begin{tabular}{|l|c|c|c|}
\hline Parameter & $\mathrm{pH} 2$ & $\mathrm{pH} 4$ & $\mathrm{pH} \mathrm{7}$ \\
\hline$k_{1}{ }^{0} / \mathrm{mol} \mathrm{cm}^{-2} \mathrm{~s}^{-1}$ & $1.0 \times 10^{-8}$ & $4.0 \times 10^{-9}$ & $3.9 \times 10^{-9}$ \\
\hline$k_{1 \mathrm{i}}{ }^{0} / \mathrm{mol} \mathrm{cm}^{-2} \mathrm{~s}^{-1}$ & $0.8 \times 10^{-13}$ & $0.5 \times 10^{-13}$ & $0.3 \times 10^{-13}$ \\
\hline$k_{3}{ }^{0} / \mathrm{mol} \mathrm{cm}^{-2} \mathrm{~s}^{-1}$ & $1.5 \times 10^{-19}$ & $3.1 \times 10^{-22}$ & $3.4 \times 10^{-25}$ \\
\hline$k_{3 \mathrm{i}}{ }^{0} / \mathrm{mol} \mathrm{cm}^{-2} \mathrm{~s}^{-1}$ & $0.86 \times 10^{-9}$ & $6.1 \times 10^{-11}$ & $1.5 \times 10^{-11}$ \\
\hline$\alpha b_{3} / \mathrm{V}^{-1}$ & 18.7 & 16.5 & 16.1 \\
\hline$\alpha b_{3 \mathrm{i}} / \mathrm{V}^{-1}$ & 9 & 5.5 & 4.0 \\
\hline$D_{\mathrm{e}} / \mathrm{cm}^{2} \mathrm{~s}^{-1}$ & $1.0 \times 10^{-9}$ & $1.0 \times 10^{-9}$ & $1.0 \times 10^{-9}$ \\
\hline$D_{\mathrm{i}} / \mathrm{cm}^{2} \mathrm{~s}^{-1}$ & $0.9 \times 10^{-14}$ & $2.0 \times 10^{-14}$ & $1.9 \times 10^{-14}$ \\
\hline$D_{\mathrm{V}} / \mathrm{cm}^{2} \mathrm{~s}^{-1}$ & $0.49 \times 10^{-17}$ & $2.3 \times 10^{-17}$ & $28 \times 10^{-17}$ \\
\hline$a / \mathrm{cm}$ & $2.0 \times 10^{-8}$ & $2.0 \times 10^{-8}$ & $2.3 \times 10^{-8}$ \\
\hline$\varepsilon$ & 45 & 25 & 20 \\
\hline$\alpha$ & 0.75 & 0.75 & 0.75 \\
\hline$E / \mathrm{V} \mathrm{cm}^{-1}$ & $2.5 \times 10^{6}$ & $2.0 \times 10^{6}$ & $2.0 \times 10^{6}$ \\
\hline
\end{tabular}


Table 4. Kinetic parameters for the passive film on 654 SMO formed in $0.5 \mathrm{M} \mathrm{Na}_{2} \mathrm{SO}_{4}$ solutions of $\mathrm{pH} \mathrm{2,} 4$ and 7.

\begin{tabular}{|l|c|c|c|}
\hline Parameter & $\mathrm{pH}$ & $\mathrm{pH}$ & $\mathrm{pH}$ \\
\hline$k_{1}^{0} / \mathrm{mol} \mathrm{cm}^{-2} \mathrm{~s}^{-1}$ & $32 \times 10^{-9}$ & $8.0 \times 10^{-9}$ & $7.9 \times 10^{-9}$ \\
\hline$k_{1 \mathrm{i}}{ }^{0} / \mathrm{mol} \mathrm{cm}^{-2} \mathrm{~s}^{-1}$ & $3.5 \times 10^{-13}$ & $3.5 \times 10^{-13}$ & $1.9 \times 10^{-13}$ \\
\hline$k_{3}{ }^{0} / \mathrm{mol} \mathrm{cm}^{-2} \mathrm{~s}^{-1}$ & $31 \times 10^{-19}$ & $3.6 \times 10^{-21}$ & $1.97 \times 10^{-25}$ \\
\hline$k_{3 \mathrm{i}}{ }^{0} / \mathrm{mol} \mathrm{cm}^{-2} \mathrm{~s}^{-1}$ & $4.9 \times 10^{-9}$ & $0.81 \times 10^{-9}$ & $0.48 \times 10^{-9}$ \\
\hline$\alpha b_{3} / \mathrm{V}^{-1}$ & 18 & 18 & 17.5 \\
\hline$\alpha b_{3 \mathrm{i}} / \mathrm{V}^{-1}$ & 7.4 & 6 & 3.6 \\
\hline$D_{\mathrm{e}} / \mathrm{cm}^{2} \mathrm{~s}^{-1}$ & $3.0 \times 10^{-9}$ & $3.5 \times 10^{-9}$ & $4.5 \times 10^{-9}$ \\
\hline$D_{\mathrm{i}} / \mathrm{cm}^{2} \mathrm{~s}^{-1}$ & $0.38 \times 10^{-14}$ & $0.57 \times 10^{-14}$ & $0.40 \times 10^{-14}$ \\
\hline$D_{\mathrm{V}} / \mathrm{cm}^{2} \mathrm{~s}^{-1}$ & $0.36 \times 10^{-17}$ & $0.26 \times 10^{-17}$ & $0.90 \times 10^{-17}$ \\
\hline$a / \mathrm{cm}^{-17}$ & $2.2 \times 10^{-8}$ & $2.0 \times 10^{-8}$ & $2.5 \times 10^{-8}$ \\
\hline$\varepsilon$ & 30 & 25 & 15 \\
\hline$\alpha$ & 0.75 & 0.78 & 0.78 \\
\hline$E / \mathrm{V} \mathrm{cm}$ & $2.5 \times 10^{6}$ & $2.5 \times 10^{6}$ & $2.0 \times 10^{6}$ \\
\hline
\end{tabular}

- The estimated values for diffusion coefficients of point defects are in broad agreement with those quoted by several authors for passive films [14,25,32,41-44]. It is worth noting that the diffusion coefficient of interstitial cations is much larger than that of cation vacancies, which once more points to the interstitial transport as mainly responsible for the metal dissolution through the film. The values of both diffusion coefficients are the highest for the film formed on 254SMO and the lowest for and the film formed on 654SMO. Bearing in mind that the concentration of $\mathrm{Fe}$ in the oxide is a function of its content in the underlying alloy $[16,45]$, such a ranking can be tentatively correlated to the fact that the Fe content in $654 \mathrm{SMO}$ is considerably lower than that of $254 \mathrm{SMO}$. The diffusion coefficient of cation vacancies seems to increase with $\mathrm{pH}$ (Tables 2-4) whereas that of interstitial cations is quasi-independent of $\mathrm{pH}$. In order to explain this trend, more detailed data on the structure of the films formed in solutions with different $\mathrm{pH}$ are obviously needed.

- The values of the electric field strength are close to those estimated by Olsson and Landolt for films formed on comparable stainless steels [31] and also to our previous estimates for films formed on ferritic steels and nickel-based alloys $[14,15,25]$. The values of the polarizability of the film/solution interface are rather high, indicating that the major part of the potential drop is actually consumed at the film/solution interface. This calculation result is in accordance with the conclusion of Olsson and Landolt [31] that a better description of very thin passive films is obtained by assuming interfacial control of the processes instead of bulk control.

- The values of the half-jump distance are of the order of those typically assumed for hopping motion processes. The values of the dielectric constant of the films are within the range usually assumed for passive films [34-37] and in general decrease with increasing $\mathrm{pH}$, which is in accordance with the trend in the capacitance values calculated from the impedance spectra (Figs 11a-13a). Such a trend can be tentatively explained by a change in the composition and thickness of the passive film with increasing $\mathrm{pH}$, as demonstrated by XPS analysis [18].

- The values given in Tables 2-4 for the diffusion coefficient of electronic current carriers $D_{\mathrm{e}}$ are rather low, albeit considerably higher than those of the ionic point defects and also significantly higher than previous estimates for the passive films on ferritic steels $[14,15,24]$. In that context, the values of $D_{\mathrm{e}}$ reported in Tables 2-4 are probably not a direct measure for the 
mobility of electronic current carriers in the film as a whole. They most probably represent the minimum value of the mobility in the depletion layer of the semiconductor oxide, which is the primary barrier for the transport of electronic current carriers. An alternative explanation of the low values of the diffusion coefficient of electronic current carriers is that the mobile ionic defects in passive films can act as electron traps, immobilising and later releasing electrons. In that connection, the low value of $D_{\mathrm{e}}$ in nanocrystalline semiconductor oxide films has been recently attributed to electrons spending a large fraction of their transit time in traps $[46,47]$. In addition, the fast relaxation of photo-excited electrons in semiconductor nanoparticles has been associated with a high density of trap states or a strong coupling between intrinsic midbandgap states and trap states [48].

\section{Conclusions}

This paper demonstrates that the Mixed-Conduction Model is able to reproduce quantitatively the electrochemical and transport properties of anodic films on several commercial highly alloyed stainless steels in sulphate solutions with a pH in the range 2 to 7 . Notably, it is evidenced that the metal dissolution through the film proceeds via two parallel paths involving the generation, transport and consumption of interstitial cations and cation vacancies. The first path is predominant in most part of the passive region and corresponds mainly to the dissolution of Fe through the oxide. Thus enhanced dissolution through the film via interstitial cations causes activation of the steels at low enough potentials in the active-to-passive transition region. The second path, mediated by cation vacancies, is responsible for transpassive dissolution of $\mathrm{Cr}$ through the oxide at high enough potentials. The progress of this reaction increases significantly the ionic conductivity of the passive film and in the transpassive region itself the dissolution processes become totally controlled by the reactions at the film/solution interface.

As the kinetic and transport properties of the passive film determine the protective ability of that film towards metal corrosion, it can be concluded that the MCM could serve as a basis for a deterministic approach to the prediction of the general corrosion rates of stainless steels and compatible materials. However, to achieve such goal, its ability to reproduce quantitatively experimental results from other techniques in addition to the electrochemical methods used in the present work is highly desirable.

\section{References}

[1] E. A. Abd El Meguid, A. A. Abd El Latif, Corros. Sci. 46 (2004) 2431-2444.

[2] A. Mahk, I. Andijani, A. Jamaluddin, S. Ahmed, Desalination 171 (2004) 289-298.

[3] E. A. Abd El Meguid, A. A. Abd El Latif, Corros. Sci. 49 (2007) 263-275.

[4] C. Liu, J. Wu, Corros. Sci. 49 (2007) 2198-2209.

[5] S. Arab, M. Abdulsalam, H.Alghamdi, Arab. J. Sci. Eng. 39 (2014) 5405-5412.

[6] T. L. S. L. Wijesinghe, D. Blackwood, J. Electrochem. Soc. 153 (2006) B178-B180.

[7] T. L. S. L. Wijesinghe, D. Blackwood, Corros. Sci. 50 (2008) 23-34.

[8] D. D. Macdonald, J. Electrochem. Soc. 139 (1992) 3434-3449.

[9] D. D. Macdonald, K. M. Ismail, E. Sikora, J. Electrochem. Soc. 145 (1998) 3141-3149.

[10] D. D. Macdonald, Pure Appl. Chem. 71 (1999) 951-978.

[11] D. D. Macdonald, in D. Feron, D. D. Macdonald, Eds, Prediction of Long Term Corrosion Behaviour in Nuclear Waste Systems, European Federation of Corrosion Publications No.36, The Institute of Materials, Minerals and Mining, Maney Publishing, London, 2003, p. 75-90. 
[12] M. Bojinov, G. Fabricius, T. Laitinen, K. Mäkelä, T. Saario, G. Sundholm, J. Electrochem. Soc. 146 (1999) 3238-3247.

[13] M. Bojinov, G. Fabricius, T. Laitinen, K. Mäkelä, T. Saario, G. Sundholm, Electrochim. Acta 45 (2000) 2029-2048.

[14] M. Bojinov, G. Fabricius, T. Laitinen, K. Mäkelä, T. Saario, G. Sundholm, Electrochim. Acta 46 (2001) 1339-1358.

[15] I. Betova, M. Bojinov, A. Englund, G. Fabricius, T. Laitinen, K. Mäkelä, T. Saario, G. Sundholm, Electrochim. Acta 46 (2001) 3627-3640.

[16] A. Rossi, B. Elsener, in Proceedings of the 12th International Corrosion Congress, Houston, USA, 1993, paper No. 71, p.2120-2130.

[17] A. Rossi, B. Elsener, Mater. Sci. Forum 185-188 (1995) 337-346.

[18] B. Elsener, A. Rossi, Mater. Sci. Forum 192-194 (1995) 225-236.

[19] T. Saario, T. Laitinen, J. Piippo, Mater. Sci. Forum 289-292 (1998) 193-202.

[20] I. Betova, M. Bojinov, T. Laitinen, K. Mäkelä, P. Pohjanne, T. Saario, Corros. Sci. 44(2002) 2675-2697.

[21] I. Betova, M. Bojinov, T. Laitinen, K. Mäkelä, P. Pohjanne, T. Saario, Corros. Sci. 44(2002) 2699-2723.

[22] J. S. Kim, W. H. A. Peelen, K. Hemmes, R. C. Makkus, Corros. Sci. 44 (2002) 635-655.

[23] V. Maurice, W. P. Yang, P. Marcus, J. Electrochem. Soc. 145(1998) 909-920.

[24] P. Schmuki, S. Virtanen, A.J. Davenport, C. Vitus, J. Electrochem. Soc. 143 (1996) 3997-4005.

[25] M. Bojinov, P. Kinnunen, T. Laitinen, K. Mäkelä, T. Saario, in Corrosion and Corrosion Protection, J. Sinclair, E. Kalman, R. Frankenthal, W. Plieth, Ed., Proceedings of the Electrochemical Society PV 2001-22, The Electrochemical Society, Inc., Pennington, NJ, USA, p.26-33.

[26] J. A. L. Dobbelaar, E. C. M. Herman, J. H. W. de Wit, Corros. Sci. 33 (1992) 765-778.

[27] L. C. Jacobs, H. P. de Vogel, P. E. Habing, J. A. L. Dobbelaar, K. Hemmes, J. H. W. de Wit, Electrochim. Acta 38 (1993) 1969-1973.

[28] N. Hara, K. Sugimoto, J. Electrochem. Soc. 138(1991) 1594-1599.

[29] P. Keller, H.-H. Strehblow, Corros. Sci. 46 (2004) 1939-1952.

[30] P. Schmutz, D. Landolt, Electrochim. Acta 45 (1999) 899-911.

[31] C.-O. A. Olsson, D. Landolt, J. Electrochem. Soc. 148 (2001) B438.

[32] X.-P. Guo, Y. Tomoe, H. Imaizumi, K. Katoh, J. Electroanal. Chem. 445 (1998) 95-103.

[33] H. Göhr, Ber. Bunsenges. Phys. Chem. 85(1981)274-280.

[34] A. Di Paola, Electrochim. Acta 34(1989) 203-210.

[35] A. Di Paola, F. Di Quarto, C. Sunseri, Electrochim. Acta 31(1986) 935-948.

[36] P. Schmuki, H. Böhni, Werkst. Korros. 42(1991) 203-207.

[37] P. Schmuki, H. Böhni, J. Electrochem. Soc. 139(1992) 1908-1913.

[38] J.-P. Petit, L. Antoni, B. Baroux, in Modifications of Passive Films, P. Marcus, B. Baroux and M. Keddam, Eds., European Federation of Corrosion Publications No.12, The Institute of Materials, London, 1994, p.91-95.

[39] I. Betova, M. Bojinov, A. Englund, G. Fabricius, T. Laitinen, K. Mäkelä, T. Saario, G. Sundholm, Electrochim. Acta 46 (2001) 3627-3640.

[40] P.Schmutz, D. Landolt, Corros. Sci. 41(1999) 2143-2163.

[41] D. D. Macdonald, S. I. Smedley, Electrochim. Acta 35 (1990) 1949-1956.

[42] E. B. Castro, Electrochim. Acta 39(1994) 2117-2123.

[43] V. Battaglia, J. Newman, J. Electrochem. Soc. 142(1995) 1423-1430.

[44] Y. F. Cheng, C. Yang, J. L. Luo, Thin Solid Films 416 (2002) 169-173. 
[45] B. Elsener, D. DeFilippo, A. Rossi, in Modifications of Passive Films, P. Marcus, B. Baroux, M. Keddam, Eds., European Federation of Corrosion Publications No.12, The Institute of Materials, London, 1994, p.6-11.

[46] L. Dloczik, O. lleperuma, I. Lauermann, L. M. Peter, E.A. Ponomarev, G. Redmond, N. J. Shaw, I. Uhlendorf, J. Phys. Chem. B 101(1997) 10281-10289.

[47] N. Kopidakis, E. A. Schiff, N.-G. Park, J. Van de Lagemaat, A. J. Frank, J.Phys. Chem. B 104 (2000) 3930-3936.

[48] N. J. Cherepy, D.B. Liston, J. A. Lovejoy, H. M. Deng, J. Z. Zhang, J. Phys. Chem. B 102(1998) 770-776. 